\title{
Prognosis assessment of CD44+/CD24- in Breast Cancer Patients: a systematic review and meta- analysis
}

Jingjing Gu

Lianyungang Second People's Hospital affiliated to Bengbu Medical College

Dandan Chen

Lianyungang Second People's Hospital affiliated to Bengbu Medical College

Zhiqiang li

Lianyungang Second People's Hospital affiliated to Bengbu Medical College,Lianyungang,China

\section{Yongliang Yang}

Lianyungang Second People's Hospital affiliated to Bengbu Medical College,Lianyungang

Zhaoming $\mathrm{Ma}$

Lianyungang Second People's Hospital affiliated to Bengbu Medical College

Guanhong Huang ( $\nabla$ hghlyg002@sina.com )

Lianyungang Second People's Hospital affiliated to Bengbu Medical College,Lianyungang

\section{Research Article}

Keywords: CD44+/CD24-, Breast cancer, Meta-analysis, Prognosis

Posted Date: August 23rd, 2021

DOl: https://doi.org/10.21203/rs.3.rs-318997/v1

License: (9) This work is licensed under a Creative Commons Attribution 4.0 International License.

Read Full License

Version of Record: A version of this preprint was published at Archives of Gynecology and Obstetrics on April 18th, 2022. See the published version at https://doi.org/10.1007/s00404-022-06402-w. 


\title{
Manuscript title:Prognosis assessment of $\mathrm{CD}^{+} / \mathrm{CD}^{-} 4^{-}$in Breast Cancer Patients: a systematic review and meta-analysis
}

\author{
Running title: Meta-analysis of CD44 ${ }^{+} \mathrm{CD} 24^{-}$Prognosis Assessment in Breast Cancer Patients
}

Authors:Jingjing $\mathrm{Gu}^{1}$,Dandan $\mathrm{Chen}^{1}$,Zhiqiang $\mathrm{Li}^{2}$,Yongliang Yang ${ }^{3}$,Zhaoming Ma*,Guanhong Huang*

${ }^{1}$ Jingjing Gu,Lianyungang Second People's Hospital affiliated to Bengbu Medical College,Lianyungang,China; ${ }^{1}$ Dandan Chen,Lianyungang Second People's Hospital affiliated to Bengbu Medical College,Lianyungang,China; ${ }^{2}$ Zhiqiang Li,Lianyungang Second People's Hospital affiliated to Bengbu Medical College,Lianyungang,China; ${ }^{3}$ Yongliang Yang,Lianyungang Second People's Hospital affiliated to Bengbu Medical College,Lianyungang,China;Co-Corresponding author:*Zhaoming Ma,Lianyungang Second People's Hospital affiliated to Bengbu Medical College,Lianyungang,China,mazhm131@126.com;Corresponding author:*Guanhong Huang,Lianyungang Second People’s Hospital affiliated to Bengbu Medical College,Lianyungang,China,hghlyg002@sina.com.

\begin{abstract}
Purpose:This meta-analysis investigated the relationships between the CD44 ${ }^{+} / \mathrm{CD} 24^{-}$phenotype and tumor size, lymph node metastasis, distant metastasis, disease-free survival (DFS), and overall survival (OS) in 8036 postoperative breast cancer patients enrolled in 23 studies. Methods:A literature search of PubMed, Medline, Cochrane, Embase, and PMC was conducted to identify eligible studies. The combined odds ratios (ORs) and $95 \%$ confidence intervals $(95 \% \mathrm{CIs}$ ) were analyzed to evaluate the relationships between the $\mathrm{CD} 44^{+} / \mathrm{CD} 24^{-}$phenotype and the pathological and biological characteristics of breast cancer patients, and the combined hazard ratios (HRs) and $95 \%$ CIs were calculated to evaluate the relationships between CD44 ${ }^{+}$CD24- and DFS and OS of breast cancer petients using Stata12.0 software. Results: The CD44 ${ }^{+} / \mathrm{CD} 24^{-}$phenotype were not related to the tumor size (tumor size $>2.0 \mathrm{~cm}$ vs $\leq 2.0 \mathrm{~cm}$, combined $\mathrm{OR}=0.98,95 \% \mathrm{CI}: 0.68-1.34, p=0.792)$ and didn't promote lymph node metastasis (lymph node metastasis vs. no lymph node metastasis, combined OR $=0.94,95 \% \mathrm{CI}: 0.71-1.26, p=0.692)$ and distant metastasis (distant metastasis vs no distant metastasis, combined OR $=$ 3.88, 95\% CI: $0.93-16.24, p=0.064)$. The $\mathrm{CD} 44^{+} / \mathrm{CD} 24-$ phenotype was negatively correlated with postoperative $\mathrm{DFS}(\mathrm{HR}=1.67,95 \%$ CI: $1.35-2.07, p<0.00001$ ) and $\mathrm{OS}$ (combined HR $=1.52,95 \% \mathrm{CI}: 1.21-1.91, p=0.0004)$. Conclusion:These results suggested expression of the $\mathrm{CD}_{4} 4^{+} / \mathrm{CD} 24^{-}$phenotype can be used as a reliable indicator of clinical prognosis and a potential therapeutic targets in breast cancer patients.
\end{abstract}

Key words: CD44+CD24; Breast cancer; Meta-analysis;Prognosis. 


\section{Declarations \\ Funds}

This research received no specific grant from any funding agency in the public, commercial or not-for-profit sectors

\section{Conflicts of interest}

We don't have a conflict of interest

Availability of data and material

I can always upload the data if needed.

\section{Code availability}

Stata12.0 and Revman5.3

Authors' contributions: Author Zhaoming Ma(Doctoral candidate)and author Guanhong Huang(Doctor)have given substantial contributions to the conception or the design of the manuscript, author Jingjing Gu and author Dandan Chen to acquisition, analysis and interpretation of the data,author Zhiqiang Li and Yongliang Yang to further review the data.All authors have participated to drafting the manuscript,author Zhaoming Ma and author Guanhong Huang revised it critically. All authors read and approved the final version of the manuscript. All authors contributed equally to the manuscript and read and approved the final version of the manuscript.

\section{Ethics approval}

Patients and the public were not involved in the design or conduct of the study.

\section{Consent to participate}

All the authors agreed to participate.

\section{Consent for publication}

All the authors agreed to publicate.

\section{Acknowledgements:}

Thanks Jingjing Gu, Dandan Chen, Zhaoming Ma, Guanhong Huang, Zhiqiang Li and Yongliang Yang for their efforts on this article.

\section{Introduction}

Breast cancer is the most common malignant tumor and the second leading cause of cancer death in women ${ }^{[1]}$. According to the statistics of the World Health Organization (WHO), more than 4 million patients are diagnosed with breast cancer every year, and more than 1 million people die of breast cancer every year ${ }^{[2]}$. According to multiple studies, breast cancer is a group of heterogeneous tumors with different proliferation rates, invasive capabilities, metastatic potential, and therapeutic effects ${ }^{[3]}$. Although there are 
many treatments, including surgery, radiotherapy, chemotherapy, endocrine therapy, targeted therapy, cytotoxic drug therapy, hormone therapy, and immunotherapy, a large proportion of breast cancer patients eventually die of breast cancer recurrence and metastasis. Therefore, early detection of sensitive prognostic markers is particularly important for the prognosis of breast cancer patients ${ }^{[4]}$. There is evidence indicating that, although many malignant tumors are clonal in nature, they contain heterogeneous cell populations with different biological characteristics, and a small portion of these are cancer stem cells $(\mathrm{CSCs})^{[5]}$. Some experts believe that these self-renewing CSCs are the main reason for the failure of cancer treatment ${ }^{[6]}$. In 2003, Al-Hajj and colleagues ${ }^{[7]}$ discovered that cells with the CD44 $/ \mathrm{CD} 24^{-}$phenotype undergo a process similar to normal stem cell self-renewal and differentiation ${ }^{[8]}$. Hence, the expression of $\mathrm{CD}^{4} 4^{+} / \mathrm{CD} 24^{-}$cells has attracted the interest of experts ${ }^{[9]}$. Hiroko Nogi found that cells with a expression of $\mathrm{CD} 44^{+} / \mathrm{CD} 24^{-}$are associated with lymph node metastasis ${ }^{[10]}$, and there are reports suggesting that cells with high expression of this phenotype are associated with poor prognosis of breast cancer ${ }^{[12]}$. $\mathrm{Lee}^{[13]}$ et al demonstrated that expression of $\mathrm{CD} 44^{+} / \mathrm{CD} 24^{-}$phenotype cells is associated with breast cancer tumor progression, and emphasized the importance of CSC-targeted therapy in the treatment of breast cancer. Other reports have put forward different viewpoints from the above ${ }^{[14]}$ so that the role of $\mathrm{CD} 44^{+} / \mathrm{CD} 24^{-}$tumor stem cells in breast cancer remains controversial ${ }^{[15]}$. The purpose of this study was to establish a meta-analysis model for investigating the relationships between cells with expression of the $\mathrm{CD} 44^{+} / \mathrm{CD} 24-$ phenotype and tumor size, lymph node metastasis, distant metastasis, disease-free survival (DFS), and overall survival (OS) in breast cancer patients.

\section{Study selection}

We searched the following combinations of medical subject words (MeSH) and text words in the PubMed, Medline, Cochrane, Embase, and PMC databases: ("breast cancer" or "breast cancer") and ("CD44" and "CD24") and ("prognosis" or "survival" or "outcome"). Then, in order to find other eligible papers avoiding the omissions of electronic retrieval methods, we further searched the references in the identified preliminary research papers and review articles. The date determining the inclusion of literature was December 2019.

\section{Data extraction and quality evaluation}

Two independent reviewers (Jingjing Gu and Dandan Chen) read the titles and abstracts of all candidate articles. If the nature of some articles could not be determined from the title or abstract, the full text was reviewed. Any differences in the two quality assessments and data collections were discussed with corresponding author until agreement was finally reached. A predefined form was used for data extraction. The extracted data included: the name of the first author, publication time, country, number of patients, patients with a expression of $\mathrm{CD} 44^{+} / \mathrm{CD} 24^{-}$phenotype, the number of tumors $>2.0 \mathrm{~cm}$, lymph node metastases, distant 
metastases, follow-up time, detection method, HR, and 95\% CI corresponding to OS and DFS. For articles that only included the KaplanMeier curve without providing HRs and $95 \%$ CIs, we used the methods in Tierney ${ }^{[17]}$ and Parmar et al ${ }^{[18]}$ to estimate HRs.And the prognosis-related survival rate was extracted from the Kaplan-Meier curve by GetData Graph digicater 2.24 software. Some papers, from which we still could not obtain the above information even after efforts to contact the author of the original material, were marked as "NA" (not available).

To ensure the quality of each document, the NOS scale ${ }^{[16]}$ bias assessment tool (Table 1) was used to evaluate the quality of the literature, and was independently completed and checked by two researchers (Jingjing Gu and Dandan Chen). Studies with a total score of 6-9 were regarded as high-quality research, and all papers of included in this meta-analysis were rated 6-9.And the following criteria had to be met: (1) all articles included in this study were cohort studies; (2) research subjects were postoperative patients diagnosed with breast cancer by pathology; (3) expression of CD44 $/ \mathrm{CD} 24^{-}$in breast cancer was detected by immunohistochemistry (IHC); (4) sufficient data were presented in the paper, including the number of patients with tumor size $>2.0 \mathrm{~cm}$, lymph node metastasis, and distant metastasis, in order to estimate the odds ratio (OR), hazard ratio (HR), and $95 \%$ confidence interval $(95 \% \mathrm{CI})$ that corresponded to the overall survival rate (OS) or disease-free survival rate (DFS), or so that we could calculate these measures based on the information in the article; and (5) the study was published in English.

\section{Exclusion criteria}

The following publications were excluded:(1)summaries, comments, letters to editors, and articles published in one or more unpublished books; (2) articles related to $\mathrm{CD} 44^{+} / \mathrm{CD} 24^{-}$, or articles that detected $\mathrm{CD} 44^{+} / \mathrm{CD} 24^{-}$in the blood; (3) articles that only reported animal experiments.

\section{Statistical Analysis}

ORs and 95\% CIs were used to estimate the relationships between tumor stem cells CD44 $/ \mathrm{CD} 24$ - and breast cancer pathological parameters (tumor size, lymph node status, distant metastasis). We evaluated the correlations between cells with expression of the CD44 ${ }^{+}$CD24- phenotype and patients' OS and DFS by HRs and 95\% CIs. The extracted data were analyzed using Stata12.0 and RevMan 5.3 analysis software (Cochrane Collaboration). In this study, OR $>1$ meant that cells with expression of the CD $44^{+} / \mathrm{CD}^{-} 4^{-}$phenotype were closely related to tumors $>2 \mathrm{~cm}$, lymph node metastasis, and distant metastasis. HR $>1$ indicated that cells with expression of the $\mathrm{CD} 44^{+} / \mathrm{CD} 24$ - phenotype were negatively correlated with OS and DFS. The Q test was used to evaluate the heterogeneity of the study, and the $\mathrm{I}^{2}$ value indicated the degree of heterogeneity. A $p$ value $>0.05$ and $\mathrm{I}^{2}<50 \%$ meant no heterogeneity, and a fixed-effect model was needed; otherwise, we selected a random-effect model ${ }^{[19]}$. In addition, we evaluated the publication bias of the studies using Begg's funnel 
plot,Begg's test and Egger's test. If the the graph appeared like a symmetrical inverted funnel and the $p$ values of Begg's test and Egger's test were both $>0.05$, this indicated that publication bias was not detected. We verified the reliability of the results by sensitivity analysis. All statistical tests in this meta-analysis were two-tailed and $p$-values $<0.05$ were considered statistically significant.

\section{Results}

Characteristics of Included Studies

According to the above search strategy, a total of 332 articles were initially retrieved. By screening the topics, eight repeated articles and 38 reviews were excluded. In total, 197 non-human experiments or non-breast cancer or non-CD44 ${ }^{+} / \mathrm{CD}^{2} 4^{-}$-related studies were excluded by reviewing the abstracts, and we excluded 66 articles that detected the expression of CD44 $/ \mathrm{CD} 24^{-}$in the blood. Finally, we included 23 studies in the meta-analysis, and the flowchart of the search strategy is shown in Figure 1. The total number of patients included in this meta-analysis was 8,036, from 5 studies on tumor size, 16 studies on lymph node status, and 5 studies on distant metastasis. We conducted 11 studies on OS and 9 studies on DFS.

Table 2 summarizes the main characteristics of the data related to the cancer stem cells $\mathrm{CD}_{4} 4^{+} / \mathrm{CD} 24^{-}$in this meta-analysis.

Correlations between the CD44 /CD24- Markers and the Pathological and Biological Characteristics of Breast Cancer Patients

The correlation between expression of the $\mathrm{CD} 44^{+} / \mathrm{CD} 24^{-}$phenotype and the tumor size in breast cancer patients is shown in Figure 2. Overall analysis showed that cells with the expression of CD44 ${ }^{+} / \mathrm{CD} 24^{-}$phenotype were not related to the tumor size (tumor size $>2.0 \mathrm{~cm}$ vs $\leq 2.0 \mathrm{~cm}$, combined OR $=0.98,95 \%$ CI: $0.68-1.34, p=0.792$, fixed-effect model), lymph node metastasis in breast cancer patients (Figure 4,lymph node metastasis vs no lymph node metastasis, combined OR =0.94, 95\% CI: 0.71-1.26, $p=0.692$,random-effect model), and distant metastasis of breast cancer patients (Figure 6, distant metastasis vs no distant metastasis, combined OR $=3.88$, 95\% CI: 0.93$16.24, p=0.064$,random-effect model).

Effects of the $C D 44^{+} / C D 24^{-}$Phenotype on Postoperative Disease-free Survival and Overall Survival

The above method was used to conduct 11 studies on the OS and nine studies on the DFS of breast cancer patients. The correlations between the expression of the CD44 $/ \mathrm{CD} 24^{-}$phenotype and DFS and OS of breast cancer patients are shown in Figures 5 and 6.The results indicated that expression of the cancer stem cell marker CD44 ${ }^{+} / \mathrm{CD} 24{ }^{-}$and DFS (Figure 8,HR $=1.67,95 \%$ CI: 1.35-2.07, $p<0.00001$, fixed-effect model) and OS (Figure 10,combined HR $=1.52,95 \%$ CI: 1.21-1.91, $p=0.0004$, fixed-effect model) were negatively correlated, and their differences were statistically significant.

Publication Bias 
Begg's funnel plot,Begg's test and Egger's test were used to evaluate publication bias. The graphs of Begg's funnel plot appeared like a symmetrical inverted,and the correlations between expression of the CD44 $/ \mathrm{CD} 24^{-}$phenotype and a patient's tumor size (Begg's test: $p=$ 0.221, Egger's test: $p=0.204$ ), lymph node metastasis (Begg's test: $p=0.344$, Egger's test: $p=0.171$ ), distant metastasis (Begg's test: $p=$ 0.462, Egger's test: $p=0.066$ ), DFS (Begg's test: $p=0.602$, Egger's test: $p=0.78$ ), and OS (Begg's test: $p=1$, Egger's test: $p=0.665$ ) showed there was no obvious publication bias.

Sensitivity Analysis

The sensitivity analysis results (Figures 12,13,14, 15 and 16) showed that the correlations between the cells that expressed the $\mathrm{CD} 44^{+} / \mathrm{CD} 24^{-}$phenotype and tumor size, lymph node metastasis, DFS, and OS of breast cancer patients were stable. However, as shown in Figure 14, the results of the correlation between expression of the CD44+/CD24- phenotype and the distant metastasis of breast cancer patients were not stable.

\section{Discussion}

Since Hamburger and other experts explicitly proposed the "cancer stem cell" (CSC) hypothesis for the first time in 1997, research on cancer stem cells has attracted much attention from researchers. The hypothesis proposes that tumors originate from a small subset of rare cells that have the ability to self-renew and differentiate into other cancer cells, thereby promoting tumor cell proliferation, tumor generation, and growth ${ }^{[37]}$. There is increasing evidence to support the CSC hypothesis ${ }^{[38]}$. Such research is mainly based on xenotransplantation experiments, in which human breast cancer cells are transplanted into immunocompromised mice. The results have shown that only CSCs (usually $<1 \%$ of malignant tumors) can produce tumors ${ }^{[39]}$, and also that CSCs are the only cells participating in tumor recurrence and metastasis ${ }^{[40]}$. Some researchers also believe that CSCs promote tumor growth, invasion, and metastasis by stimulating blood vessels to obtain sufficient blood and nutrition ${ }^{[41]}$. Some experts have suggested that CSCs in human breast cancer are related to recurrence and metastasis in breast cancer patients $^{[42]}$, and that breast cancer stem cells induce local lymph node metastasis in breast cancer patients ${ }^{[43]}$. Al-Hajj and colleagues proposed for the first time that cells with expression of the CD44 $/ \mathrm{CD} 24^{-}$phenotype in breast cancer show the characteristics of tumor stem cells ${ }^{[44]}$. Many subsequent studies have shown that cells with expression of the CD44 ${ }^{+} / \mathrm{CD}_{24}$ phenotype have tumorigenic ability and invasive characteristics ${ }^{[45]}$. Some experts suggested that breast cancer phenotype $\mathrm{CD}_{4} 4^{+} / \mathrm{CD} 24^{-}$cells have greater invasive ability in vitro and greater metastatic ability in vivo than other cells ${ }^{[46]}$. Studies have shown that expression of the $\mathrm{CD} 44^{+} / \mathrm{CD} 24^{-}$phenotype is associated with DFS and OS in breast cancer patients ${ }^{[47]}$. However, the role of the CSC phenotype $\mathrm{CD} 44^{+} / \mathrm{CD} 24^{-}$in breast cancer remains controversial. The research results of Mylona et al showed that there was no obvious correlation between cells with expression of the $\mathrm{CD}^{-} 4^{+} / \mathrm{CD} 24^{-}$phenotype and DFS and OS 
of postoperative patients ${ }^{[15]}$. Here, we investigated the correlations between the CSC CD44 $/$ CD24- phenotype and the pathological and biological characteristics of breast cancer patients, and the effects of this phenotype on the prognosis of breast cancer patients. We found that cells with the expression of CD44 ${ }^{+} \mathrm{CD} 24^{-}$phenotype were not related to the tumor size (tumor size $>2.0 \mathrm{~cm}$ vs $\leq 2.0 \mathrm{~cm}$, combined $\mathrm{OR}=0.98,95 \%$ CI: $0.68-1.34, p=0.792$, fixed-effect model) and didn't promot local lymph node metastasis (lymph node metastasis vs. no lymph node metastasis, combined OR $=0.94,95 \%$ CI: 0.71-1.26, $p=0.692$, random-effect model) and distant metastasis (distant metastasis vs no distant metastasis, combined OR $=3.88,95 \%$ CI: 0.93-16.24, $p=0.064$,randomeffect model). Expression of the CD44 $/ \mathrm{CD} 24^{-}$marker was negatively correlated with postoperative DFS (HR $=1.67,95 \%$ CI: $1.35-2.07$, $p<0.00001$,fixed-effect model) and OS (combined HR $=1.52,95 \%$ CI: $1.21-1.91, p=0.0004$,fixed-effect model), and their differences were statistically significant.

The CSC CD44 $/ \mathrm{CD} 24-$ phenotype has always been a research hot spot. Many investigators ${ }^{[48,49]}$ have a strong interest in the mechanism of the $\mathrm{CD}_{4} 4^{+} / \mathrm{CD} 24^{-}$phenotype in breast cancer since there has recently been renewed interest in CSCs. Hence, we felt that the $\mathrm{CD} 44^{+} / \mathrm{CD} 24^{-}$phenotype still has a certain value and significance in predicting the prognosis of breast cancer patients. Some meta-analyses have previously studied the correlations between the CD44 $/ C D 24$ phenotype of cancer stem cells and the pathological and biological characteristics of breast cancer patients, and there is also a correlation between the $\mathrm{CD}_{4} 4^{+} / \mathrm{CD} 24-$ phenotype and prognosis of breast cancer patients. Zhou ${ }^{[50]}$ suggested that expression of the $\mathrm{CD} 44^{+} / \mathrm{CD} 24-$ phenotype is not correlated with tumor size and lymphatic metastasis in breast cancer patients, but is negatively correlated with the OS of breast cancer patients. However, Wang's study found that expression of the CD44/CD24-phenotype was not significantly associated with the OS of breast cancer patients ${ }^{[51]}$. The two meta-analysis results are different, which highlights and emphasizes the necessity of our meta-analysis. Compared with the studies of Zhou and Wang, our meta-analysis proved that expression of the $\mathrm{CD} 44^{+} / \mathrm{CD} 24^{-}$phenotype is not closely related to tumor size, lymph node metastasis, and distant metastasis in breast cancer patients, but negatively correlated with DFS and OS. In support of our results, we included more research samples found through more search channels. Our meta-analysis involved a total of 23 studies, including 8,036 breast cancer patients. More importantly, we did not find heterogeneity or publication bias, and the sensitivity analysis also suggested that the results are stable on the correlation between the expression of the CD44 $/ \mathrm{CD} 24$ phenotype and the tumor size, lymph node metastasis,DFS and OS in breast cancer patients. Therefore, we conclude that breast cancer cells with expression of the $\mathrm{CD} 44^{+} / \mathrm{CD} 24-$ phenotype are not related to the pathological and biological characteristics of postoperative patients with breast cancer, and the phenotype can be used as a tumor marker to predict the prognosis of breast cancer patients. Moreover, it can be a clinical predictor of potential therapeutic targets for breast cancer patients. 
Although our research has many advantages, our study still had certain limitations. For example, on the correlation between cells with expression of the $\mathrm{CD} 44^{+} / \mathrm{CD} 24$ phenotype and distant metastasis, although obvious publication bias was not found in the results, the sensitivity analysis indicated that the results were not stable. There might be several causes for this. First, although we have checked English websites such as PubMed, Medline, Cochrane, Embase, and PMC,there were some unpublished or non-English studies that we did not collect. Second, the breast cancer patients included in the study may have been treated with different treatment methods, which would have a certain impact on the outcome of the study. Third, some studies we included only had Kaplan-Meier survival curves, so that there may have been some deviations in extracting survival data from the survival curves. Fourth, in the studies we included, the authors' follow-up times for patients were different, which may have had a certain impact on the survival data of our study. Fifthly, although the cancer stem cell $\mathrm{CD} 44^{+} / \mathrm{CD} 24^{-}$phenotype was extracted by IHC in the studies we included, the cut-off values were different. All of the above factors may cause deviations in the research results.

In summary, the results of this study indicated that, in breast cancer patients, tumor cells with expression of the $\mathrm{CD} 44^{+} / \mathrm{CD} 24-$ phenotype didn't promote tumor tissue growth, lymph node metastasis, and distant metastasis. However,they were closely related to DFS and OS. Therefore, we concluded that the cancer stem cell CD44 ${ }^{+} \mathrm{CD} 24^{-}$phenotype can be used as a reliable indicator for the clinical prognosis of breast cancer patients and a potential therapeutic target.

\section{REFERENCES}

[1]Dowling EC, Klabunde C, Patnick J, Ballard-Barbash R.Breast and cervical cancer screening programme implementation in 16 countries.J Med Screen.2010;17:139-146.

[2]Siegel RL,Miller KD,Fuchs HE.Cancer Statistics,2021. CA Cancer J Clin.2021;71(1):7-33.

[3]Jemal A, Bray F, Center MM, Ferlay J, Ward E, Forman D.Global cancer statistics.CA Cancer J Clin.2011;61:69-90.

[4]Yanping Chen, Jinlian Song, Yuhong Jiang.Predictive value of CD44 and CD24 for prognosis and chemotherapy response in invasive breast ductal carcinoma.Int J Clin Exp Pathol.2015;8(9):11287-11295.

[5]Dalerba P, Cho RW, Clarke MF Cancer stem cells: modelsand concepts. Annu Rev Med.2007;58:267-284.

[6]Shan J, Shen J, Liu L, et al. Nanog regulates self-renewal of cancer stem cell through IGF pathway in human hepatocellular carcinoma. Hepatology.2012;56:1004-1014.

[7]Dontu G, Al-Hajj M, Abdallah WM et al. Stem cells in normal breast development and breast cancer. Cell Prolif.2003;36: $59-72$. 
[8]Al-Hajj M, Wicha MS, Benito-Hernandez A et al. Prospective identification of tumorigenic breast cancer cells. Proc Natl Acad Sci USA .2003;100: 3983-3988.

[9]Kenji Hashimoto,Chikako Shimizu,Hitoshi Tsuda,Immunohistochemical detection of breast cancer stem cells in hormone receptorpositive breast cancer and their role in response to endocrine therapy and clinical outcome. Oncology.2012;82:168-174.

[10]Hiroko Nogi.Impact of CD44+/CD24- cells on non-sentinel axillary lymph node metastases in sentinel node-positive breast cancer.Oncology reports.2011;25:1109-1115.

[11] Ricardo S, Vieira AF, Gerhard R, Leitao D, Pinto R, Cameselle-Teijeiro JF, Milanezi F, Schmitt F, Paredes J.Breast cancer stem cell markers CD44, CD24 and ALDH1:expression distribution within intrinsic molecular subtype.J Clin Pathol. 2011;64(11):937-946.

[12] HE Lee, JH Kim,YJ Kim.An increase in cancer stem cell population after primary systemic therapy is a poor prognostic factor in breast cancer.British Journal of Cancer.2011;104(11):1730-1738.

[13]Mylona E, Giannopoulou I, Fasomytakis E, Nomikos A, Magkou C, Bakarakos P, Nakopoulou L.The clinicopathologic and prognostic significance of CD44+/CD24(-/low) and CD44-/CD24+ tumor cells in invasive breast carcinomas. Hum Pathol.2008;39(7):1096-1102.

[14]Nilgün Kapucuo glua,Kemal Kürs, atBozkurta,The clinicopathological and prognostic significance of CD24, CD44,CD133,ALDH1 expressions in invasive ductal carcinoma of the breast CD44/CD24 expression in breast cancer.Research and Practice.2015;211:740-747.

[15]Andreas Stang.Critical evalution of the Newcastle-Ottawa Scale for the assessment of the quality of nonrandomized syudies in meta-ananlyses.European Journal of Epidemiologh.2010;25(9):603-605.

[16]Tierney JF, Stewart LA, Ghersi D, Burdett S, Sydes MR. Practical methods for incorporating summary time-to-event data into meta-analysis. Trials.2007;8:1-16.

[17]Parmar MK, Torri V, Stewart L.Extracting summary statistics to perform meta-analyses of the published literature for survival endpoints. Stat Med. 1998; 17: 2815-2834.

[18]Mantel N, Haenszel W.Statistical aspects of the analysis of data from retrospective studies of disease. J Natl Cancer Inst. 1959;22:719-748.

[19]Qiu H, Fang X, Luo Q, Ouyang G.Cancer stem cells: a potential target for cancer therapy. Cell Mol Life Sci. 2015;72:3411-24.

[20]Gabriella Honeth, Pär-Ola Bendahl, Markus Ringnér.The CD44 + /CD24 - phenotype is enriched in basal-like breast tumors.Breast Cancer Research. 2008;10:R53. 
[21]Alexandra Giatromanolaki ,Efthimios Sivridis,Aliki Fiska.The CD44+/CD242 phenotype relates to 'triple-negative' state and unfavorable prognosis in breast cancer patients.Med Oncol.2011;28:745-752.

[22]James M. Reuben,Bang-Ning Lee,Hui Gao.Primary breast cancer patients with high risk clinicopathologic features have high percentages of bone marrow epithelial cells with ALDH activity and CD44 + CD24 lo cancer stem cell phenotype.Eur J

Cancer.2011;47(10): 1527-1536.

[23]Mohamed A. H. Ahmed,Mohammed A. Aleskandarany,Emad A. Rakha.A CD44 2 /CD24 + phenotype is a poor prognostic marker in early invasive breast cancer.Breast Cancer Res Treat.2012;133:979 - 995.

[24]Gulnur Guler,Serdar Balci,Stefan Costinean.Stem cell-related markers in primary breast cancers and associated metastatic lesions.Modern Pathology.2012;37: 1 - 7.

[25]Julia Y. S. Tsang,Yu-Hua Huang,Ming-Hua Luo.Cancer stem cell markers are associated with adverse biomarker profiles and molecular subtypes of breast cancer.Breast Cancer Res Treat.2012;136:407 - 417.

[26]A. Giordano, H. Gao,E. N. Cohen.Clinical relevance of cancer stem cells in bone marrow of early breast cancer patients.Annals of Oncology. 2013;24: $2515-2521$.

[27]Agnieszka Adamczyk,Joanna A. Niemiec,Aleksandra Ambicka.CD44/CD24 as potential prognostic markers in node-positive invasive ductal breast cancer patients treated with adjuvant chemotherapy.J Mol Hist.2014;45:35 - 45.

[28]Diego de Mendonca,Marcia Silveira Graudenz,Sidia Maria Callegari-Jacques

.Expression of cancer stem cell markers in basal and penta-negative breast carcinomas - A study of a series of triple-negative tumors.Pathology-Research and Practice. 2014;210:432 - 439.

[29]HaiShan Zhao, HongTao Tang, QingHuanXiao.The Hedgehog signaling pathway is associated with poor prognosis in breast cancer patients with the CD44 + /CD24 - phenotype.MOLECULAR MEDICINE REPORTS.2016;14: 5261-5270.

[30]AnitaBane,AliciaViloria-Petit,Dushanthi.Pinnaduwage.Clinical-pathologic significance of cancer stem cell marker expression in familial breast cancers.Breast Cancer Res Treat.2013;140:195 - 205.

[31]An Na Seo,Hee Jin Lee,Eun Joo Kim.Expression of breast cancer stem cell markers as predictors of prognosis and response to trastuzumab in HER2-positive breast cancer.British Journal of Cancer.2016;114:1109 - 1116.

[32]Iris Rabinovich,Ana Paula Martins Sebastião,Rubens Silveira Lima.Cancer stem cell mark ALDH1 and CD44+/CD24- phenotype and their progress impact in invasive ductal carcinoma.

[33]Eleni Mylona MD, Ioanna Giannopoulou BSc, Emmanouil Fasomytakis BSc.The clinicopathologic and prognostic significance of CD44+/CD24-/low and CD44- /CD24 +tumor cells in invasive breast carcinomas.Human Pathology.2008;39:1096 - 1102. 
[34]Yan Lin,Ying Zhong,Heng Guan.CD44 +/CD24 - phenotype contributes to malignant relapse following surgical resection and chemotherapy in patients with invasive ductal carcinoma.J Exp Clin Cancer Res.2012;31:59.

[35]H Raza Ali, Sarah-Jane Dawson, Fiona M Blows.Cancer stem cell markers in breast cancer:pathological, clinical and prognostic significance.Breast Cancer Research.2011;13:R118.

[36]Benny K. Abraham,Peter Fritz,Monika McClellan.Prevalence of CD44+/CD24-/low Cells in Breast CancerMay Not Be Associated with Clinical Outcome

but May Favor Distant Metastasis.Clinical Cancer Research.2005;11:1154-1159.

[37]Sebastian Aulmann MD,Nina Waldburger MD, Reduction of CD44+/CD24-breast cancer cells by conventional cytotoxic chemotherapy.Human Pathology.2010;41:574-581.

[38]H Raza Ali1,Sarah-Jane Dawson,Cancer stem cell markers in breast cancer:pathological,clinical and prognostic significance.Breast Cancer Researchesearch.2011;13:1-15.

[39]Reya T,Morrison SJ, Clarke MF, Weissman IL.Stem cells, cancer, and cancer stem cells. Nature.2001;414:105-111.

[40]Hilbe W,Dirnhofer S, Oberwasserlechner F, Schmid T, Gunsilius E, Hilbe G, et al.CD133 positive endothelial progenitor cells contribute to the tumour vasculature in non-small cell lung cancer.J Clin Pathol.2004;57:965-969.

[41]Wu S, Yu L, Wang D, Zhou L, Cheng Z, Chai D, et al. Aberrant expression of CD133 in non-small cell lung cancer and its relationship to vasculogenic mimicry. BMC Cancer. 2012;12:535.

[42]Song Z, Yue W, Wei B, Wang N, Li T, Guan L, Shi S, Zeng Q, Pei X and Chen L.Sonic hedgehog pathway is essential for maintenance of cancer stem-like cells in human gastric cancer.PLoS One.2011;6:1-13.

[43]Ahmed MA, Aleskandarany MA, Rakha EA, Moustafa RZ,Benhasouna A, Nolan C, Green AR, Ilyas M, Ellis IO A CD44(-)/CD24 (+) phenotype is a poor prognostic marker inearly invasive breast cancer.Breast Cancer Res Treat. 2011;39:1865-1868.

[44]Pandit TS, Kennette W, Mackenzie L, Zhang G, Al-Katib W,Andrews J, Vantyghem SA, Ormond DG, Allan AL, Rodenhiser DI, Chambers AF, Tuck AB. Lymphatic metastasis of breast cancer cells is associated with differential gene expression profiles that predict cancer stem cell-like properties and the ability to survive, establish and grow in a foreign environment. Int J Oncol.2009;35:297-308.

[45]Kaipparettu BA, Malik S, Konduri SD, Liu W, Rokavec M, vander Kuip H, Hoppe R, Hammerich-Hille S, Fritz P, Schroth W,Abele I, Das GM, Oesterreich S, Brauch H. Estrogen-mediated downregulation of CD24 in breast cancer cells:Int J Cancer.2008;123:66-72. 
[46]S. Ricardo, A.F. Vieira, R. Gerhard, et al.Breast cancer stem cell markers CD44,CD24 and ALDH1:expression distribution within intrinsic molecular subtypes.J. Clin. Pathol. 2011;64:937-946.

[47]Ko Yu-Chan,Choi Hack Sun,Liu Ren.Inhibitory Effects of Tangeretin, A Citrus Peel-Derived Flavonoid, on Breast Cancer Stem Cell Formation through Suppression of Stat3 Signaling.Molecules.2020;25:2599.

[48]Bai Jie,Chen Wei-Bin,Zhang Xiao-Yu.HIF-2 $\alpha$ regulates CD44 to promote cancer stem cell activation in triple-negative breast cancer via PI3K/AKT/mTOR signaling. World J Stem Cells.2020;12:87-99.

[49]Alshaer Walhan,Alqudah Dana A,Wehaibi Suha.Downregulation of STAT3, $\beta$-Catenin, and Notch-1 by Single and Combinations of siRNA Treatment Enhance Chemosensitivity of Wild Type and Doxorubicin Resistant MCF7 Breast Cancer Cells to Doxorubicin.Int J Mol Sci.2019;20:3696.

[50]Liheng Zhou,Yiwei Jiang, Tingting Yan,The prognostic role of cancer stem cells in breast cancer.a meta-analysis of published literatures:Breast Cancer Res Treat.2010;122:795-801.

[51]Zhu Wang,QianqianWang.Prognotic significance of CD44 and CD24 in breast cancer:a meta-analysis.In JBiol markers.2017;32:75-82.

Table I ( The quality of the included studies assessed by NOS)

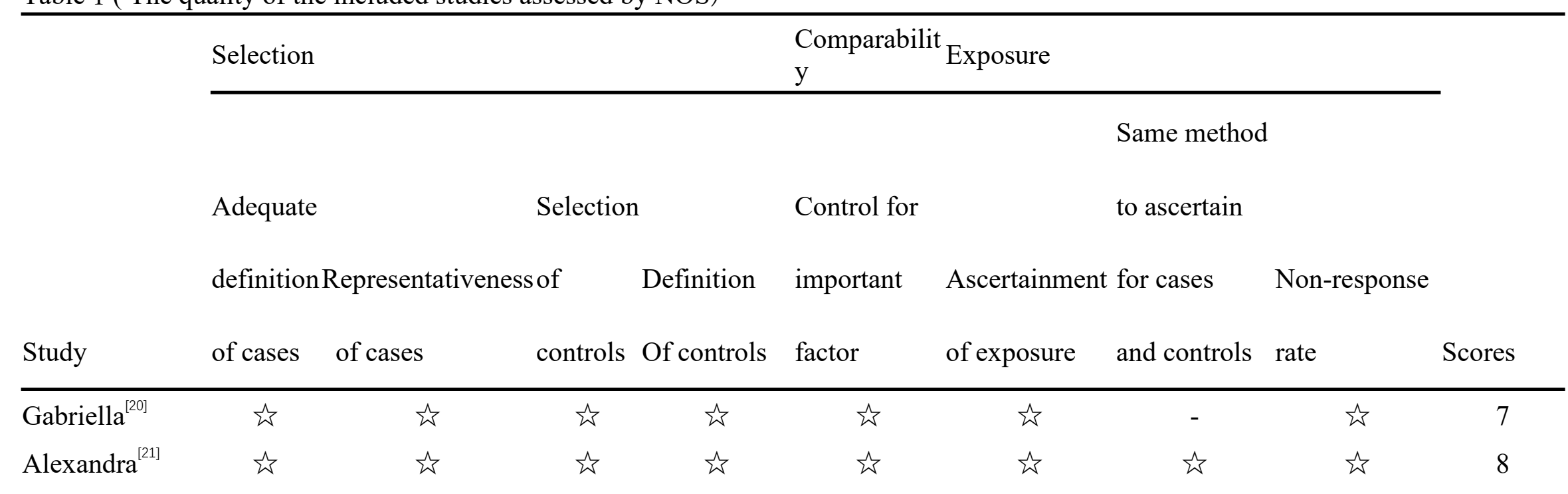




\begin{tabular}{|c|c|c|c|c|c|c|c|c|}
\hline Hiroko $^{[10]}$ & 为 & is & $\sum$ & $\sum\langle$ & $\sum$ & 弥 & is & - \\
\hline James $^{[22]}$ & 放 & 弥 & 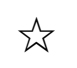 & 岤 & - & 弥 & 弥 & is \\
\hline Mohamed $^{[23]}$ & is & is & 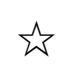 & is & 拧 & $\hat{s}$ & $\hat{s}$ & $\hat{\Sigma}$ \\
\hline Gulnur $^{[24]}$ & 弥 & 访 & 头 & 访 & - & 放 & 访 & 放 \\
\hline Julia $^{[25]}$ & is & is & $i$ & $\hat{\Sigma}$ & $i$ & is & $i$ & - \\
\hline Giordano $^{[26]}$ & is & 弥 & 弥 & 拧 & 拧 & 放 & $i$ & 岤 \\
\hline Agnieszka ${ }^{[27]}$ & is & 嵉 & is & 光 & 放 & 放 & 放 & 约 \\
\hline $\operatorname{Diego}^{[28]}$ & 访 & is & $i$ & 放 & - & is & $i$ & $\hat{\sim}$ \\
\hline Nilgün ${ }^{[14]}$ & 功 & is & is & - & 放 & is & is & - \\
\hline $\mathrm{Chen}^{[4]}$ & it & is & $\sum$ & - & is & is & - & is \\
\hline Zhao $^{[29]}$ & 访 & 访 & 头 & 访 & 访 & 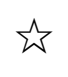 & is & - \\
\hline Bane $^{[30]}$ & is & 访 & 头 & 访 & - & 放 & is & - \\
\hline $\mathrm{Seo}^{[31]}$ & 放 & 放 & 放 & th & 岤 & 放 & is & - \\
\hline Rabinovich $^{[32]}$ & 弥 & is & is & 放 & - & is & 访 & - \\
\hline Eleni $^{[33]}$ & $i^{2}$ & $\hat{s}$ & $i$ & 约 & 论场 & $i^{2}$ & $\omega^{2}$ & 弥 \\
\hline $\operatorname{Lin}^{[34]}$ & 弥 & is & 访 & 头 & - & is & is & - \\
\hline $\operatorname{Ali}^{[35]}$ & is & is & 头 & 头 & 弥弥 & 访 & is & 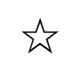 \\
\hline Abraham $^{[36]}$ & is & is & 访 & 头 & 访 & 放 & is & 次 \\
\hline Aulmann $^{[37]}$ & 放 & it & ¿ & th & - & 放 & 访 & - \\
\hline Hashimoto ${ }^{[0]}$ & 放 & $\hbar$ & 㶦 & 㶦 & 弥 & 访 & 访 & - \\
\hline
\end{tabular}



$\operatorname{Lee}^{[12]}$
$\stackrel{\wedge}{\imath}$
㶦
is
is
㶦

Table 2- Main characteristics of the included studies on $\mathrm{CD}^{+} 4^{+} / \mathrm{CD} 24^{-}$.Abbreviations:NA,not available.

\begin{tabular}{|c|c|c|c|c|c|c|c|c|c|c|c|c|}
\hline Name & Year & Country & Marker & $\begin{array}{c}\text { Techn- } \\
\text { ology }\end{array}$ & Cohort & $\begin{array}{c}\text { CD44 }{ }^{+} / \text {CD24 } \\
(+) \text { Tumor } \\
\text { size }>2 \mathrm{~cm}\end{array}$ & $\begin{array}{c}\mathrm{CD}^{\mathrm{CD}^{+}}{ }^{-} \\
\mathrm{CD}^{-} \\
(+) \\
\text {LN }\end{array}$ & $\begin{array}{c}\text { CD44 }^{+} / \mathrm{C} \\
\text { D24 }^{-} \\
(+) \\
\text {M (+) }\end{array}$ & $\begin{array}{l}\text { Follow - } \\
\text { up time }\end{array}$ & $\begin{array}{c}\text { Cut-off } \\
\text { value }\end{array}$ & \multicolumn{2}{|c|}{$\begin{array}{cc}\text { OS } & \text { DFS } \\
\text { HR95\%CI( Minimu } \\
\text { m-Maximum value) }\end{array}$} \\
\hline Gabriella & 2008 & Sweden & $\mathrm{CD} 44^{+} / \mathrm{CD} 24$ & $\mathrm{IHC}$ & 240 & 40 & 45 & 23 & NA & NA & NA & NA \\
\hline Alexandra & 2011 & Greece & $\mathrm{CD} 44^{+} / \mathrm{CD} 24^{-}$ & $\mathrm{IHC}$ & 139 & NA & 8 & NA & NA & $10 \%$ & NA & NA \\
\hline Hiroko & 2011 & Japan & $\mathrm{CD} 44^{+} / \mathrm{CD} 24^{-}$ & $\mathrm{IHC}$ & 271 & NA & 21 & NA & NA & $10 \%$ & NA & NA \\
\hline
\end{tabular}




\begin{tabular}{|c|c|c|c|c|c|c|c|c|c|c|c|c|}
\hline JamesM & 2012 & USA & $\mathrm{CD} 44^{+} / \mathrm{CD} 24^{-}$ & IHC & 66 & NA & 18 & NA & NA & $3 \%$ & NA & NA \\
\hline Mohamed & 2011 & UK & $\mathrm{CD} 44^{+} / \mathrm{CD} 24$ & IHC & 306 & 22 & 15 & 11 & NA & NA & NA & NA \\
\hline Gulnur & 2012 & USA & $\mathrm{CD} 44^{+} / \mathrm{CD} 24$ & IHC & 338 & NA & 8 & 7 & NA & NA & NA & NA \\
\hline Julia & 2012 & HongKong & $\mathrm{CD} 44^{+} / \mathrm{CD} 24$ & IHC & 540 & NA & 109 & NA & NA & NA & NA & NA \\
\hline Giordano & 2012 & USA & $\mathrm{CD} 44^{+} / \mathrm{CD} 24$ & IHC & 103 & NA & 32 & NA & 60 & NA & NA & $(1.10-68.99)$ \\
\hline Agnieszka & 2014 & Poland & $\mathrm{CD} 44^{+} / \mathrm{CD} 24^{-}$ & IHC & 156 & NA & 15 & NA & NA & NA & NA & NA \\
\hline Diego & 2014 & Brazil & $\mathrm{CD} 44^{+} / \mathrm{CD} 24^{-}$ & IHC & 28 & 12 & 6 & NA & NA & NA & NA & NA \\
\hline Nilgün & 2015 & Turkey & $\mathrm{CD} 44^{+} / \mathrm{CD} 24^{-}$ & IHC & 57 & NA & 31 & NA & NA & Scores $>3$ & NA & NA \\
\hline Chen & 2015 & China & $\mathrm{CD} 44^{+} / \mathrm{CD} 24^{-}$ & IHC & 120 & NA & 42 & 23 & 160 & NA & $\begin{array}{c}2.12(1.25- \\
3.57)\end{array}$ & $\begin{array}{c}2.05(1.22- \\
3.46)\end{array}$ \\
\hline Zhao & 2016 & China & $\mathrm{CD} 44^{+} / \mathrm{CD} 24$ & IHC & 242 & NA & NA & NA & 80 & NA & $\begin{array}{c}1.98(0.83- \\
4.72)\end{array}$ & $\begin{array}{c}1.43(0.99- \\
2.07)\end{array}$ \\
\hline
\end{tabular}




\begin{tabular}{|c|c|c|c|c|c|c|c|c|c|c|c|c|}
\hline Bane & 2013 & Canada & $\mathrm{CD} 44^{+} / \mathrm{CD} 24$ & IHC & 262 & 17 & 18 & NA & 148 & Scores $>3$ & $\begin{array}{c}1.18(0.62- \\
2.27)\end{array}$ & NA \\
\hline Seo & 2016 & UK & $\mathrm{CD} 44^{+} / \mathrm{CD} 24$ & $\mathrm{IHC}$ & 241 & NA & 41 & NA & 118.1 & $10 \%$ & $\begin{array}{c}2.02(1.14- \\
3.57)\end{array}$ & $\begin{array}{c}2.29(1.28- \\
4.09)\end{array}$ \\
\hline $\begin{array}{c}\text { Rabinovic } \\
\mathrm{h}\end{array}$ & 2018 & Italy & $\mathrm{CD}_{4} 4^{+} / \mathrm{CD} 24$ & $\mathrm{IHC}$ & 140 & NA & 9 & NA & 180 & $5 \%$ & $\begin{array}{c}1.63(0.68- \\
3.89)\end{array}$ & $\begin{array}{c}2.86(0.68- \\
14.06)\end{array}$ \\
\hline Eleni & 2008 & Greece & $\mathrm{CD} 44^{+} / \mathrm{CD} 24$ & IHC & 147 & NA & NA & NA & 135 & $10 \%$ & $\begin{array}{c}0.7(0.22- \\
2.21)\end{array}$ & $\begin{array}{c}0.76(0.21- \\
2.15)\end{array}$ \\
\hline Yanlin & 2007 & China & $\mathrm{CD} 44^{+} / \mathrm{CD} 24$ & IHC & 147 & NA & NA & NA & 84 & NA & $\begin{array}{c}2.24(1.35- \\
3.72)\end{array}$ & $\begin{array}{c}1.96(1.16- \\
3.31)\end{array}$ \\
\hline Ali & 2011 & UK & $\mathrm{CD} 44^{+} / \mathrm{CD} 24$ & IHC & 4152 & NA & NA & NA & 102 & NA & $\begin{array}{c}0.73(0.4- \\
1.33)\end{array}$ & NA \\
\hline Abraham & 2005 & India & $\mathrm{CD} 44^{+} / \mathrm{CD} 24$ & IHC & 122 & 20 & 16 & 3 & 85.4 & NA & $\begin{array}{c}1.46(0.67- \\
3.18)\end{array}$ & $\begin{array}{c}1.22(0.67- \\
2.22)\end{array}$ \\
\hline Aulmann & 2010 & Germany & $\mathrm{CD} 44^{+} / \mathrm{CD} 24$ & IHC & 50 & NA & NA & NA & 41 & $5 \%$ & $\begin{array}{c}2.61(0.49- \\
14.07)\end{array}$ & NA \\
\hline Hashimoto & 2012 & Janpan & $\mathrm{CD} 44^{+} / \mathrm{CD} 24$ & IHC & 77 & NA & NA & NA & 26.4 & $10 \%$ & $\begin{array}{c}1.06(0.26- \\
4.29)\end{array}$ & NA \\
\hline Lee & 2011 & Korea & $\mathrm{CD} 44^{+} / \mathrm{CD} 24$ & IHC & 92 & NA & NA & NA & 36 & $5 \%$ & NA & $\begin{array}{c}1.78(0.51- \\
6.15)\end{array}$ \\
\hline
\end{tabular}


Table 2: $\left(\mathrm{CD}_{4} 4^{+} / \mathrm{CD} 24-(+) \mathrm{LN}(+)\right.$ means the number of lymph node metastases in patients with high expression of $\mathrm{CD}^{-} 4^{+} / \mathrm{CD} 24-$ phenotype cells, $\mathrm{CD} 44^{+} / \mathrm{CD} 24^{-}(+) \mathrm{M}$ means the number of distant metastases in patients with high expression of phenotype cells.)

Figure 1-The search strategy flow chart of this meta-ananlysis.

Figure 2-Forest plot was assessed for the correlation of CD44 ${ }^{+} / \mathrm{CD} 24^{-}$with tumor size $>2 \mathrm{~cm}$ in breast cancer. Heterogeneity chi-squared $=$ $1.88($ d.f. $=4), p=0.758$, I-squared (variation in OR attributable to heterogeneity) $=0.0 \%$, Test of $\mathrm{OR}=1: \mathrm{z}=0.26, p=0.792$.

Figure 3-Begg's funnel plot was used to detect publication bias on the correlation of CD44 $/ \mathrm{CD} 24^{-}$with tumor size in breast cancer.Begg's test $p=0.221$;Egger's test $p=0.204$.

Figure 4-Forest plot was assessed for the correlation of CD44 ${ }^{+} / \mathrm{CD} 24^{-}$with Lymph node metastasis in breast cancer. Heterogeneity chisquared $=31.35($ d.f. $=15) p=0.008$, I-squared (variation in OR attributable to heterogeneity) $=52.2 \%$, Estimate of between-study variance Tau-squared $=0.1599$, Test of $\mathrm{OR}=1: \mathrm{z}=0.40, p=0.692$.

Figure 5-Begg's funnel plot was assessed for publication bias on the correlation of CD44 $/ \mathrm{CD} 24^{-}$with Lymph node metastasis in breast cancer.Begg's test $p=0.344$; Egger's test $p=0.171$.

Figure 6-Forest plot was assessed for the correlation of CD44+/CD24- with distant metastasis in breast cancer.Heterogeneity chi-squared $=36.20($ d.f. $=4) p=0.0001$,I-squared (variation in OR attributable to heterogeneity) $=89.0 \%$,Estimate of between-study variance Tausquared $=2.1575$, Test of $\mathrm{OR}=1: \mathrm{z}=1.85, p=0.064$. 
Figure 7-Begg's funnel plot was assessed for publication bias on the correlation of CD44+/CD24- with distant metastasis in breast cancer.Begg's test $p=0.462$;Egger's test $p=0.066$.

Figure 8-Forest plot was assessed for the correlation of CD44+/CD24- with DFS in breast cancer.Heterogeneity chi-squared $=8.65(\mathrm{~d} . \mathrm{f} .=$ 8); $p=0.373$; I-squared (variation in ES attributable to heterogeneity) $=7.5 \%$; Test of $\mathrm{ES}=1: \mathrm{z}=4.77 ; p<0.00001$.

Figure 9-Begg's funnel plot was used to detect publication bias on the correlation of CD44+/CD24- with DFS in breast cancer.Begg's test $p=0.602$;Egger's test $p=0.78$.

Figure 10-Forest plot was assessed for the correlation of CD44 ${ }^{+} / \mathrm{CD} 24^{-}$with OS in breast cancer. Heterogeneity chi-squared $=12.94$ (d.f. =10) $p=0.227 \mathrm{I}$-squared (variation in ES attributable to heterogeneity) $=22.7 \%$; Test of $\mathrm{ES}=1: \mathrm{z}=3.58, p=0.0004$.

Figure 11-Begg's funnel plot was assessed for publication bias on the correlation of CD44+/CD24- with OS in breast cancer.Begg's test $p=1$;Egger's test $p=0.665$.

Figure $12-$ Sensitivity analysis was assessed for the stability of results about the correlation of $\mathrm{CD}^{-} 4^{+} / \mathrm{CD}^{-} 4^{-}$with tumor size $>2.0 \mathrm{~cm}$ in breast cancer.

Figure 13-Sensitivity analysis was used to detect the stability of results about the correlation of CD44 ${ }^{+}$CD24- with Lymph node metastasis in breast cancer.

Figure 14-Sensitivity analysis was used to detect the stability of results about the correlation of CD44 ${ }^{+} / \mathrm{CD}^{-} 4^{-}$with distant metastasis in breast cancer.

Figure 15-Sensitivity analysis was used to detect the stability of results about the correlation of CD44 ${ }^{+} / \mathrm{CD}^{-} 4^{-}$with DFS in breast cancer. 
Figure 16 Sensitivity analysis was used to detect the stability of results about the correlation of $\mathrm{CD}^{4} 4^{+} / \mathrm{CD} 24^{-}$with $\mathrm{OS}$ in breast cancer. 


\section{Figures}

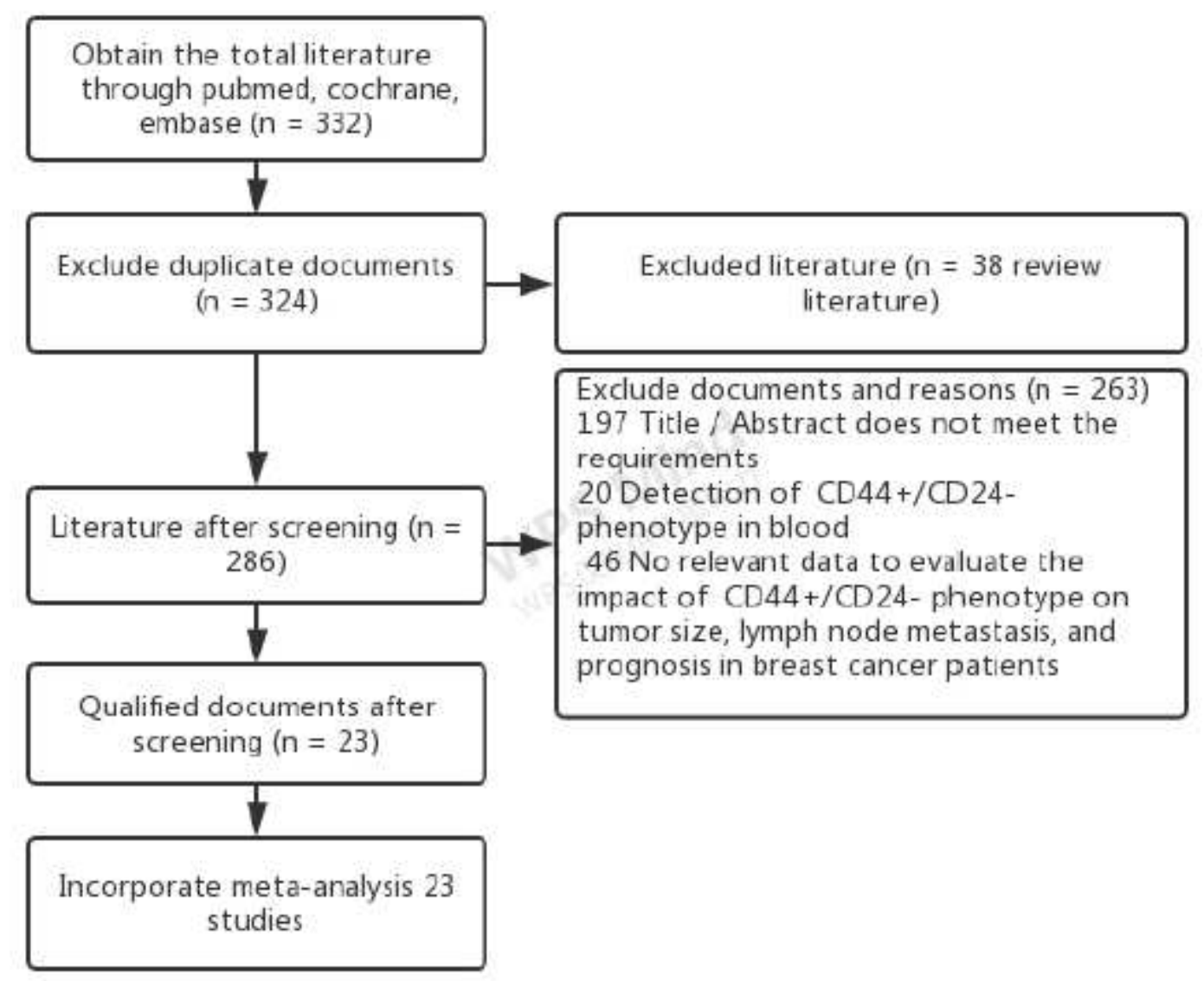

Figure 1

The search strategy flow chart of this meta-ananlysis. 


\begin{tabular}{|c|c|c|}
\hline Adraham (2005) & $0.67(0.25,1.82)$ & 13.02 \\
\hline Gabrela (2005) & $1.31(0.61,2.83)$ & 17.56 \\
\hline Mohaned (2012) & $1.02(0.57,1.81)$ & 33.35 \\
\hline Anltabane (2013) & $0.92(0.47,1.82)$ & 25.85 \\
\hline Dlego (2014) & $0.59(0.18,1.89)$ & 10.21 \\
\hline Overal (1-squared $-0.0 \%, p-0.758$ ) & $0.96(0.68,1.34)$ & 100.00 \\
\hline
\end{tabular}

\section{Figure 2}

Forest plot was assessed for the correlation of CD44+/CD24- with tumor size $>2 \mathrm{~cm}$ in breast cancer. Heterogeneity chi-squared $=1.88($ d.f. $=4$ ), $p=0.758$, I-squared (variation in OR attributable to heterogeneity) $=0.0 \%$, Test of $O R=1: z=0.26, p=0.792$. 
Begg's funnel plot with pseudo $95 \%$ confidence limits

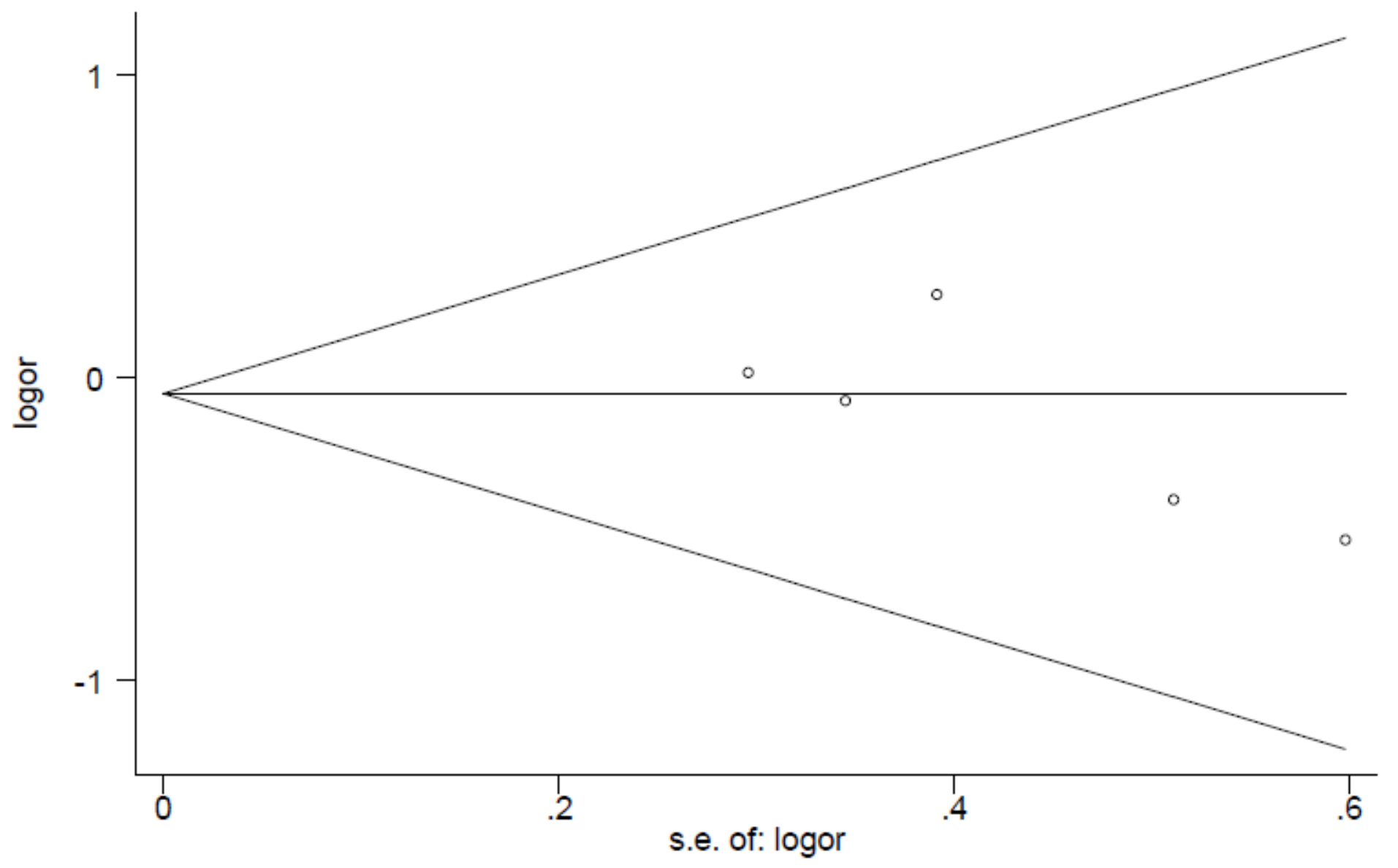

Figure 3

Begg's funnel plot was used to detect publication bias on the correlation of CD44+/CD24- with tumor size in breast cancer.Begg's test $p=0.221$;Egger's test $p=0.204$. 


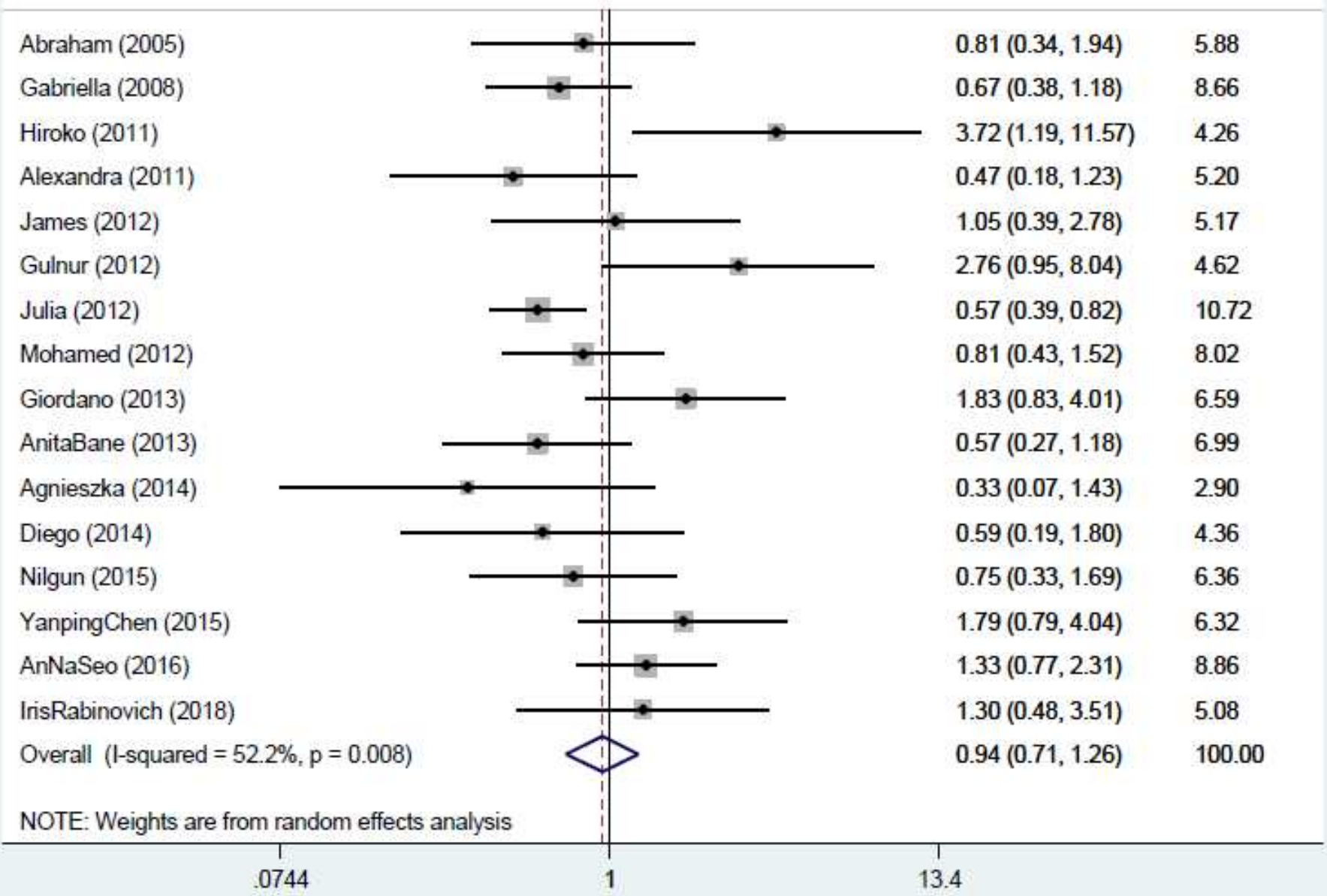

\section{Figure 4}

Forest plot was assessed for the correlation of CD44+/CD24- with Lymph node metastasis in breast cancer. Heterogeneity chisquared $=31.35$ (d.f. $=15) p=0.008$, I-squared (variation in OR attributable to heterogeneity) $=52.2 \%$, Estimate of between-study variance Tau-squared $=0.1599$, Test of $O R=1: z=0.40$, $p=0.692$. 
Begg's funnel plot with pseudo $95 \%$ confidence limits

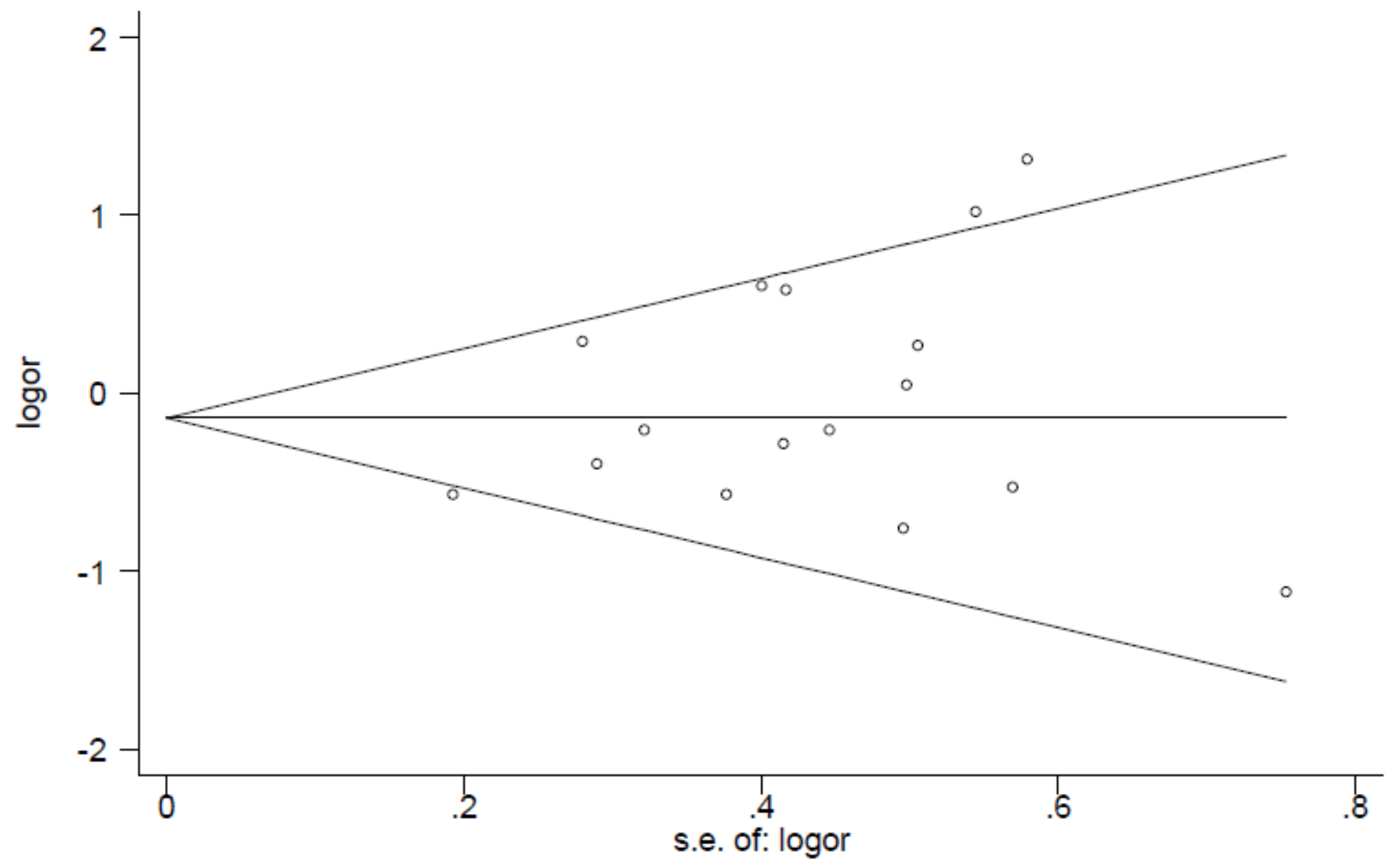

Figure 5

Begg's funnel plot was assessed for publication bias on the correlation of CD44+/CD24- with Lymph node metastasis in breast cancer.Begg's test $p=0.344$ Egger's test $p=0.171$. 


\begin{tabular}{|c|c|c|}
\hline Abranam $\{2005\}$ & $5.81(0.92,36.77)$ & 17.56 \\
\hline Gabnela (2008) & $1.02(0.56,1.84)$ & 23.76 \\
\hline Gunur (2012) & $70.00(6.30, \pi 77.87)$ & 14.57 \\
\hline Monamea (2012) & $0.52(0.26,1.02)$ & 23.44 \\
\hline Yanplingchen (2015) & $16.36(4.55,58.76)$ & 20.68 \\
\hline Overal (1-6quared $-89.0 \%, p-0.000)$ & $3.88(0.93,16.24)$ & 100.00 \\
\hline NOTE: Weights are tom random eneds anaysls & & \\
\hline
\end{tabular}

\section{Figure 6}

Forest plot was assessed for the correlation of CD44+/CD24- with distant metastasis in breast cancer.Heterogeneity chi-squared $=36.20($ d.f. $=4) p=0.0001$, I-squared (variation in OR attributable to heterogeneity) $=89.0 \%$,Estimate of between-study variance Tausquared $=2.1575$, Test of $O R=1: z=1.85, p=$ 0.064 . 
Begg's funnel plot with pseudo $95 \%$ confidence limits

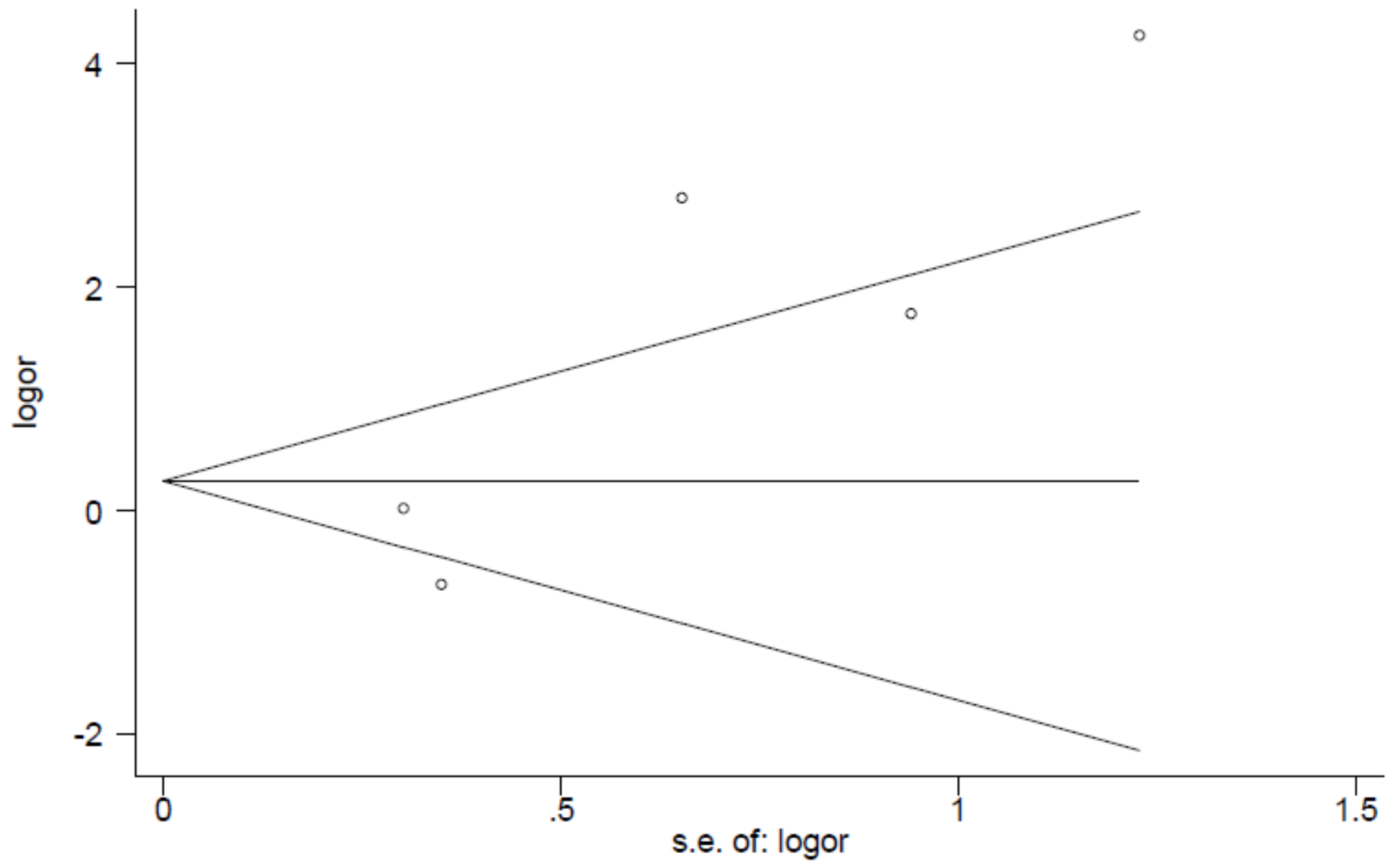

Figure 7

Begg's funnel plot was assessed for publication bias on the correlation of CD44+/CD24- with distant metastasis in breast cancer.Begg's test $p=0.462$;Egger's test $p=0.066$. 


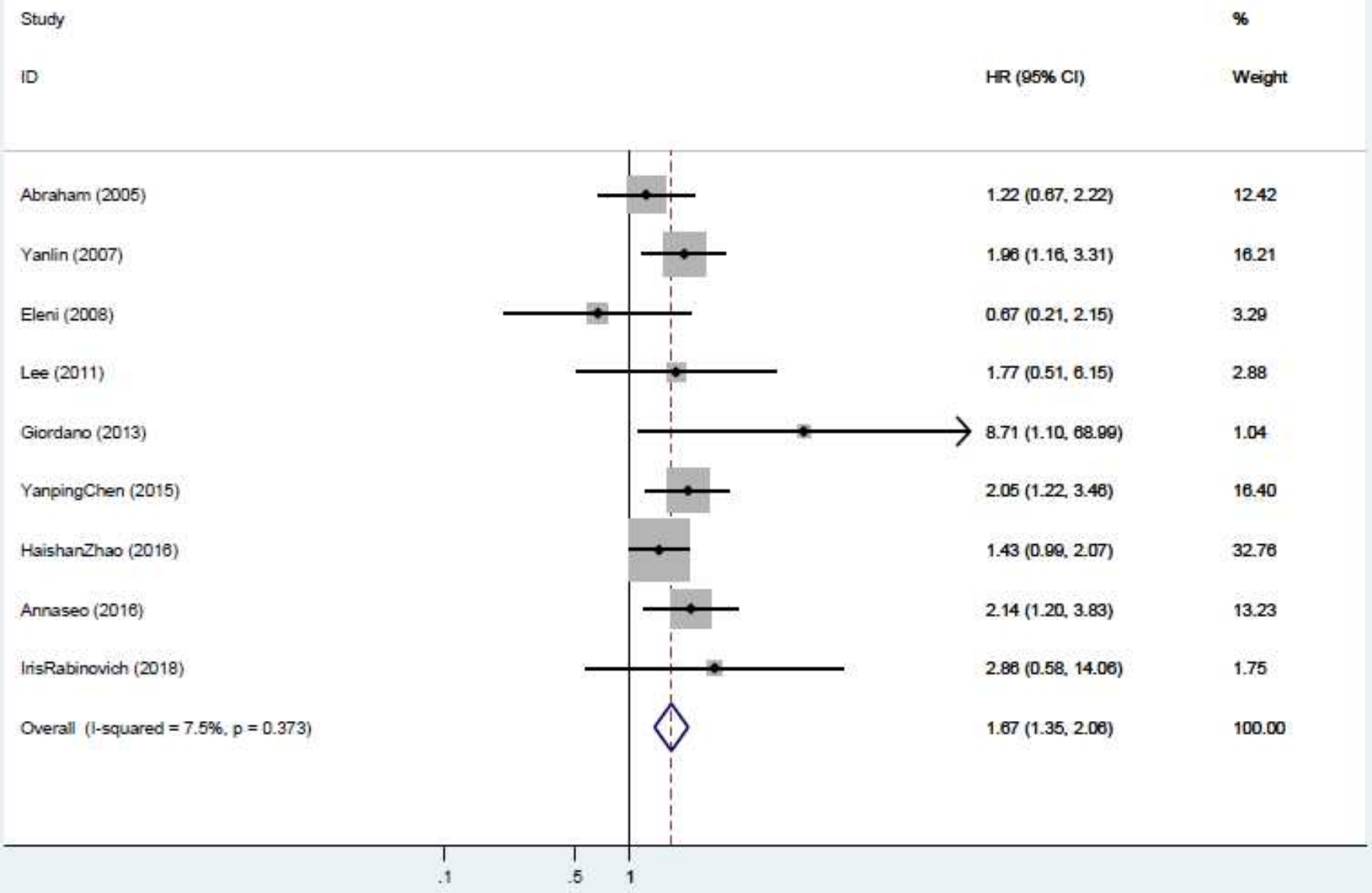

\section{Figure 8}

Forest plot was assessed for the correlation of CD44+/CD24- with DFS in breast cancer.Heterogeneity chisquared $=8.65$ (d.f. $=8) ; p=0.373$; I-squared (variation in ES attributable to heterogeneity) $=7.5 \%$; Test of $E S=1: z=4.77 ; p<0.00001$. 
Begg's funnel plot with pseudo $95 \%$ confidence limits

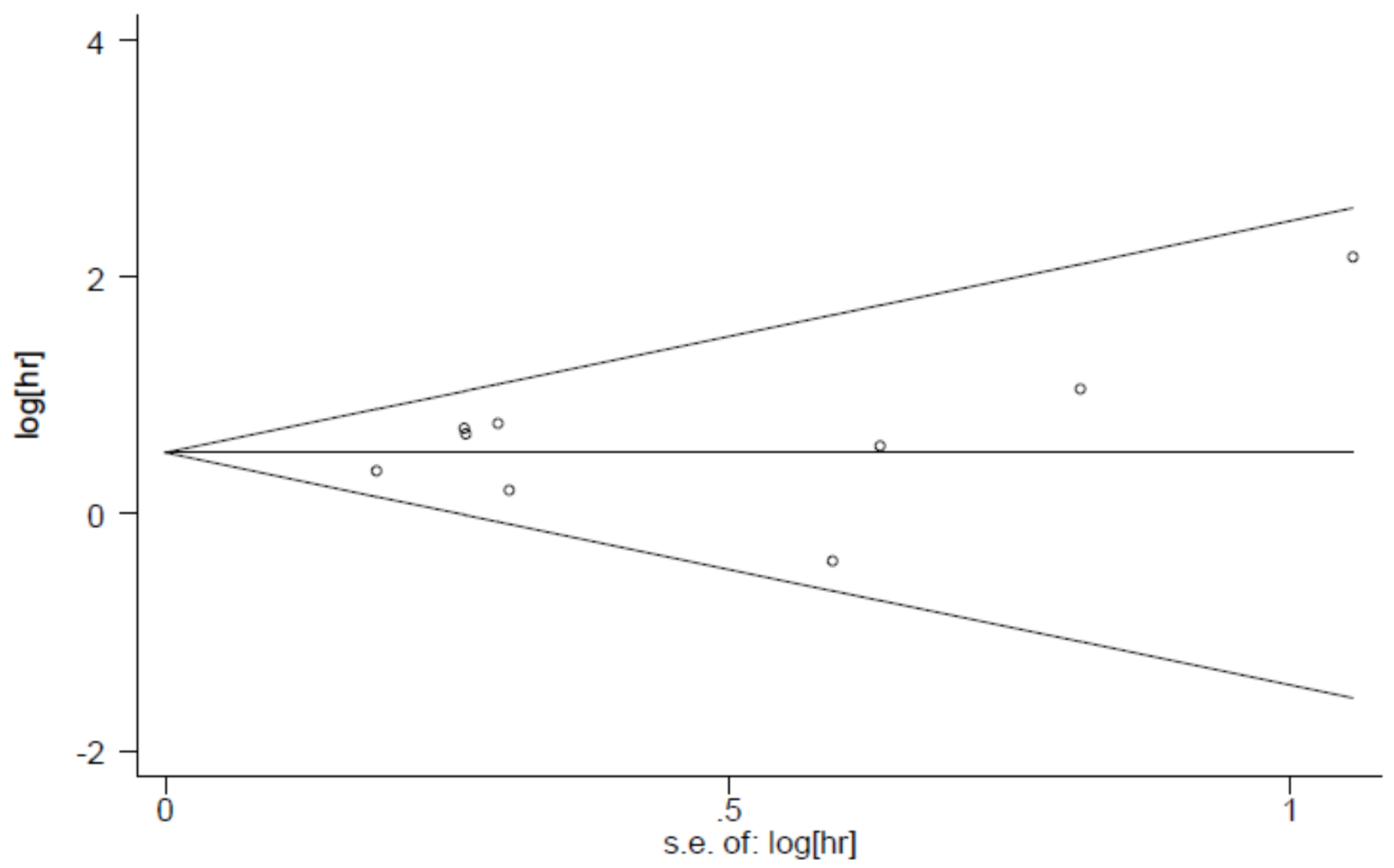

\section{Figure 9}

Begg's funnel plot was used to detect publication bias on the correlation of CD44+/CD24- with DFS in breast cancer.Begg's test $p=0.602$;Egger's test $p=0.78$. 
Study

\%

ID

HR (95\% Cl)

Weight

Abraham (2005)

Yanlin (2007)

Eleni (2008)

Aulmann (2010)

Ali (2011)

Hashimoto (2012)

AnitaBane (2013)

YanpingChen (2015)

HaishanZhao (2016)

AnnaSeo (2016)

IrisRabinovich (2018)

Overall $(1-$ squared $=22.7 \%, p=0.227)$

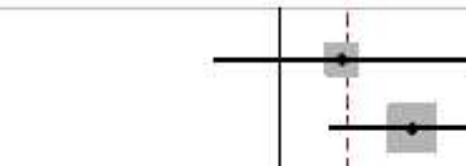

$1.46(0.67,3.18)$

8.67

$2.24(1.35,3.72) \quad 20.48$

$0.70(0.22,2.21)$

3.95

$2.63(0.49,14.07)$

1.86

$0.73(0.40,1.33)$

14.58

$1.06(0.26,4.28)$

2.87

$1.19(0.62,2.27)$

12.48

$2.12(1.25,3.59)$

18.89

$1.98(0.83,4.72)$

6.96

$1.81(0.46,7.04)$

2.59

$1.63(0.68,3.89)$

6.91

$1.52(1.21,1.91)$

100.00

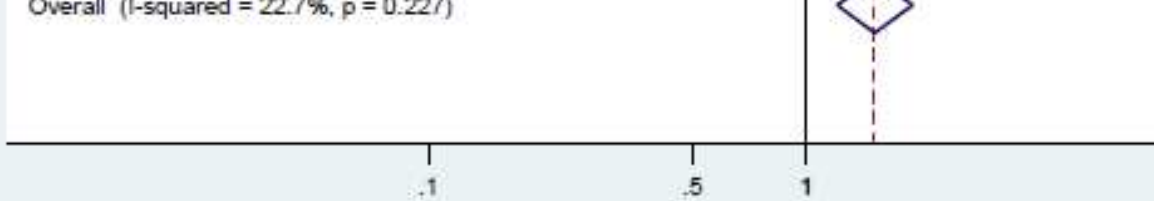

2.000

\section{Figure 10}

Forest plot was assessed for the correlation of CD44+/CD24- with OS in breast cancer. Heterogeneity chisquared $=12.94$ (d.f. $=10) p=0.227$ I-squared (variation in ES attributable to heterogeneity) $=22.7 \%$; Test of $E S=1: z=3.58, p=0.0004$. 


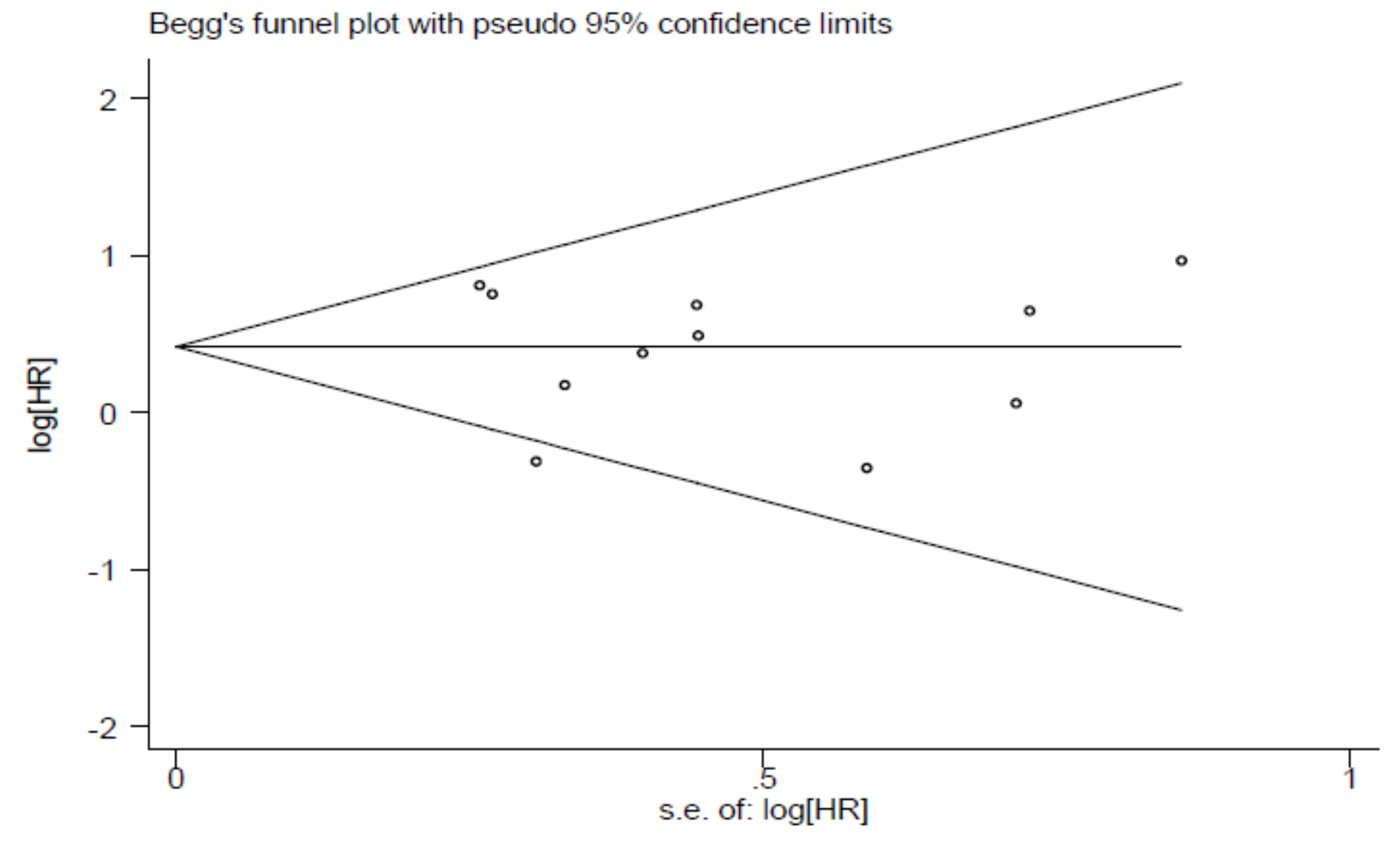

Figure 11

Begg's funnel plot was assessed for publication bias on the correlation of CD44+/CD24- with OS in breast cancer.Begg's test $p=1$;Egger's test $p=0.665$. 
Meta-analysis fixed-effects estimates (exponential form)

Study ommited

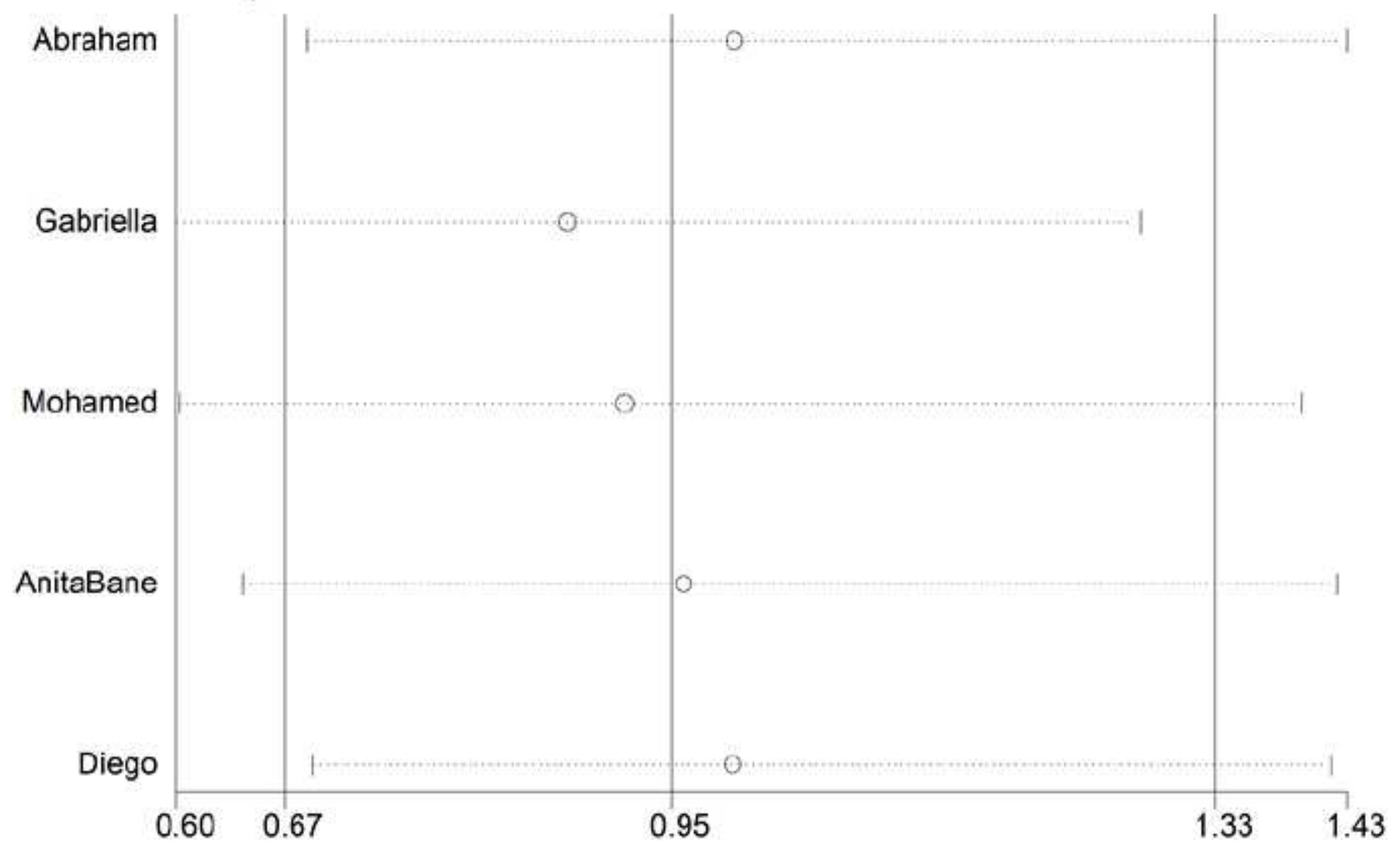

\section{Figure 12}

Sensitivity analysis was assessed for the stability of results about the correlation of CD44+/CD24- with tumor size $>2.0 \mathrm{~cm}$ in breast cancer. 


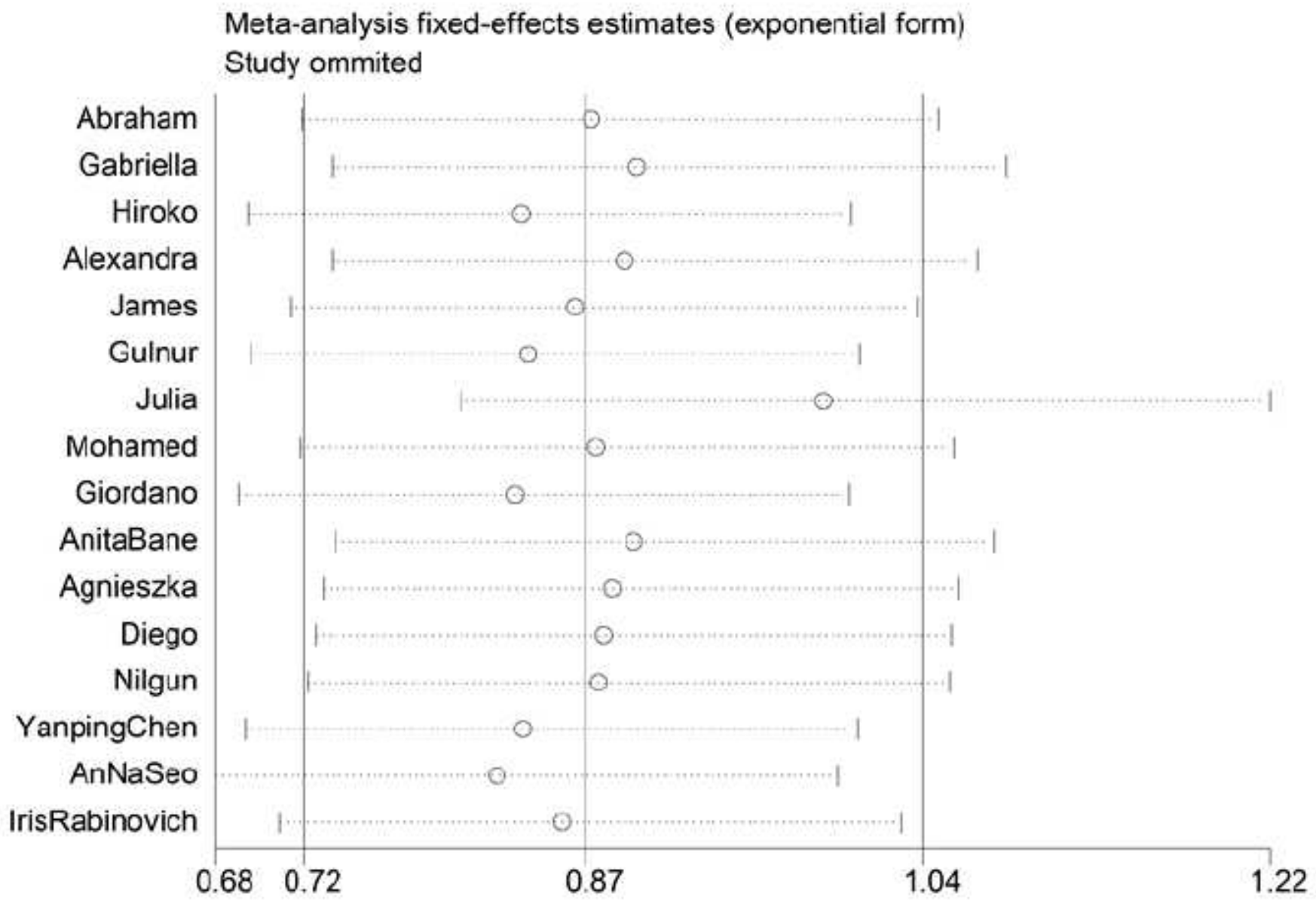

Figure 13

Sensitivity analysis was used to detect the stability of results about the correlation of CD44+/CD24- with Lymph node metastasis in breast cancer. 


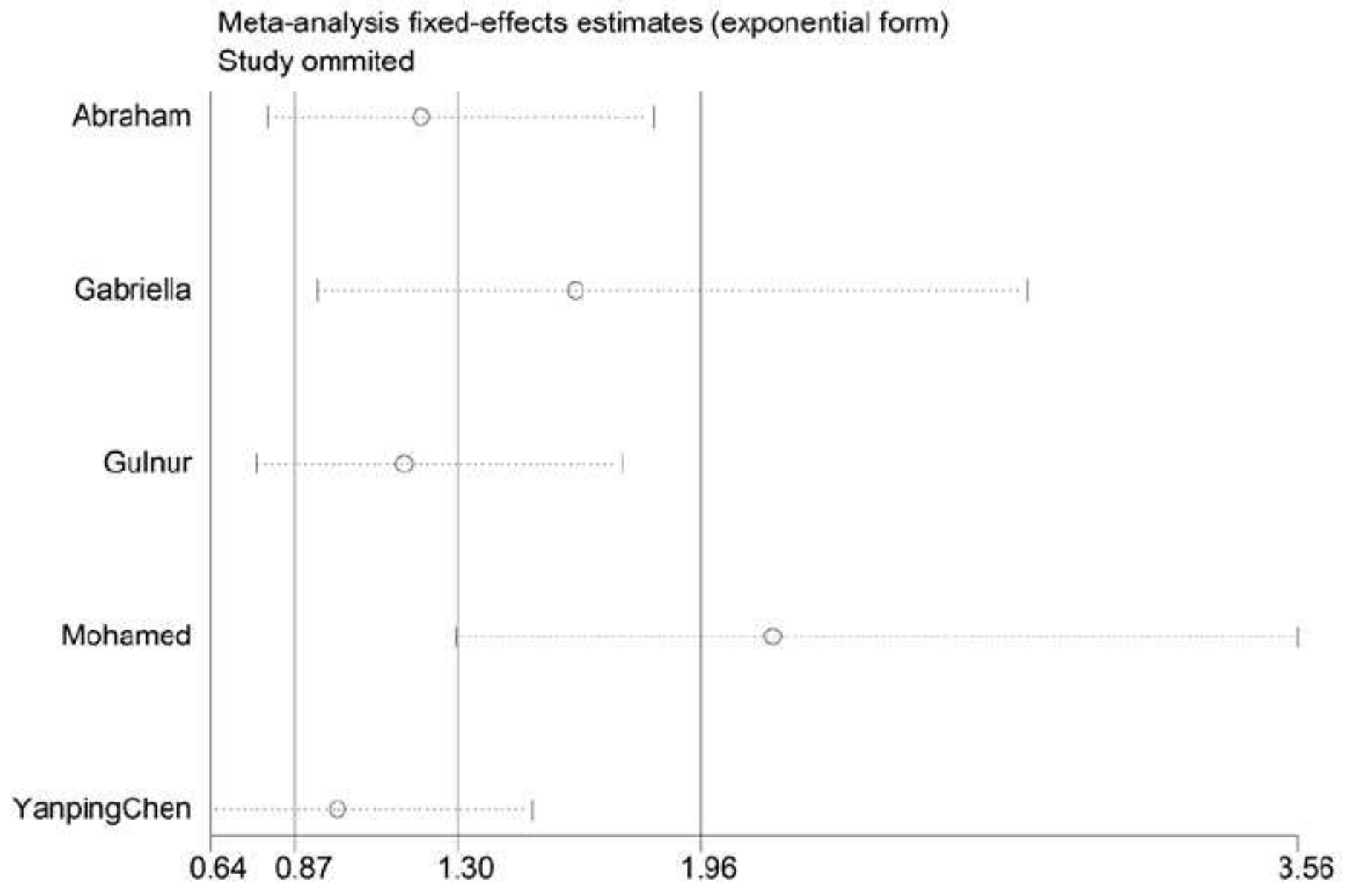

Figure 14

Sensitivity analysis was used to detect the stability of results about the correlation of CD44+/CD24- with distant metastasis in breast cancer. 


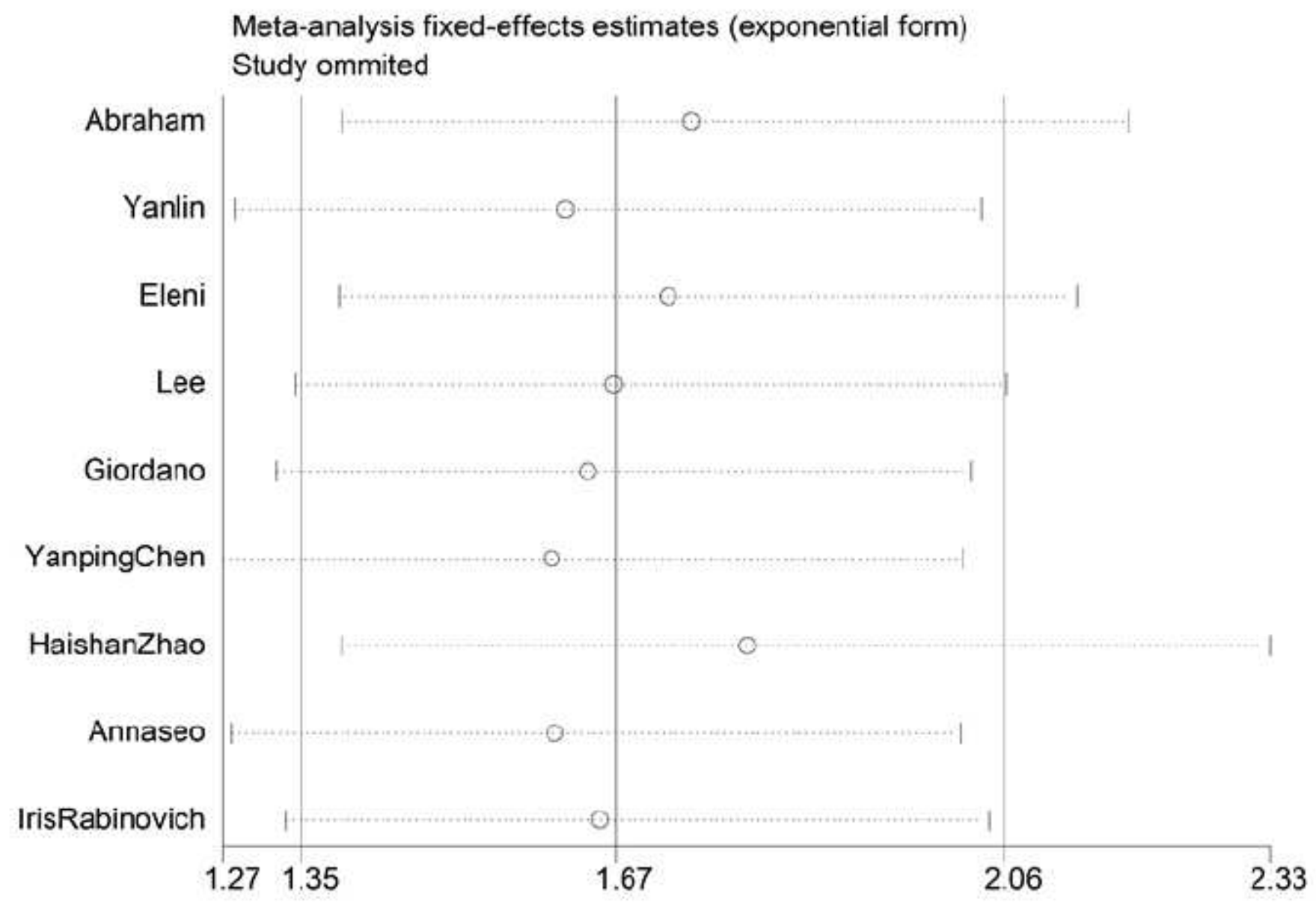

\section{Figure 15}

Sensitivity analysis was used to detect the stability of results about the correlation of CD44+/CD24- with DFS in breast cancer. 
Meta-analysis fixed-effects estimates (exponential form)

Study ommited

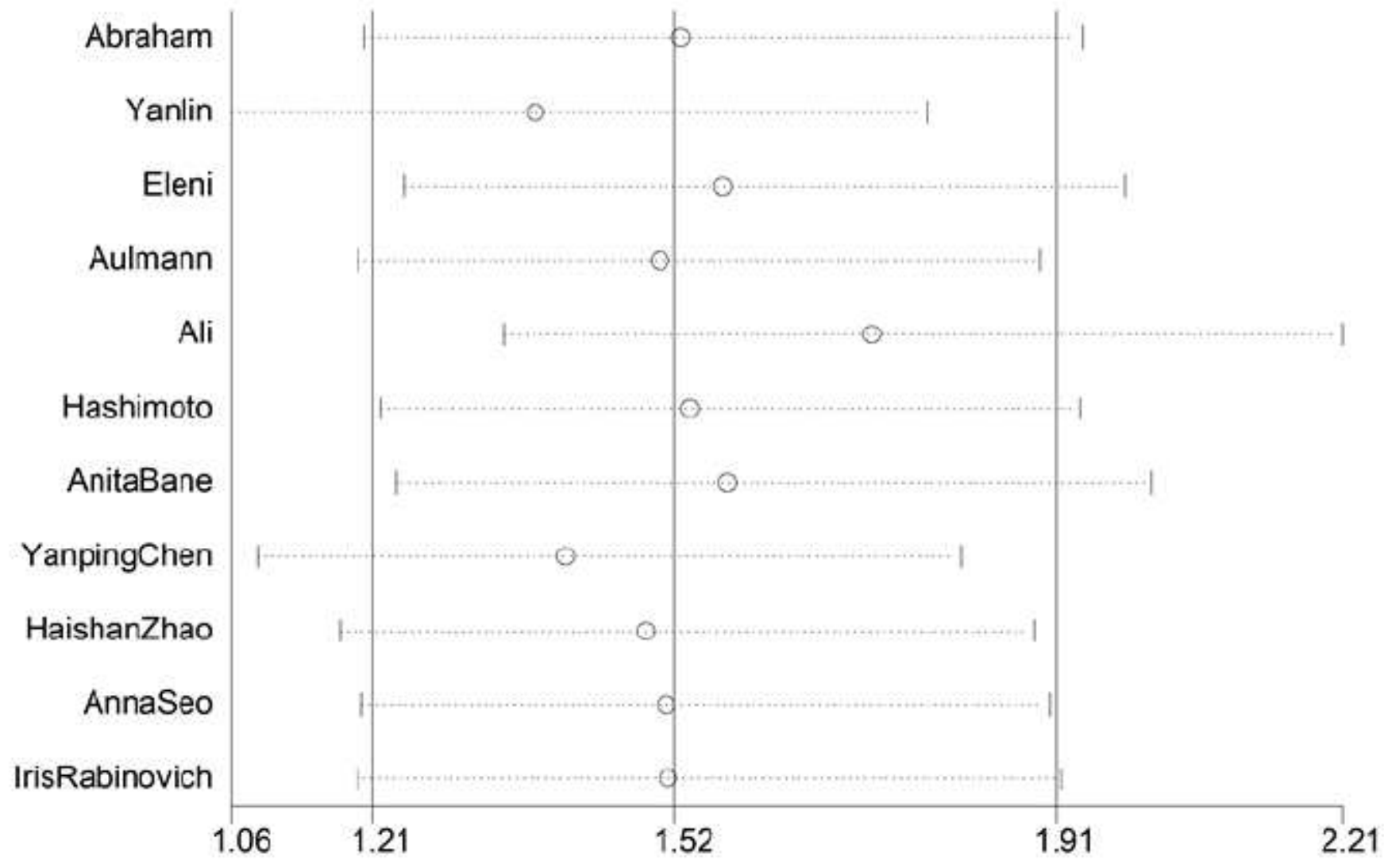

\section{Figure 16}

Sensitivity analysis was used to detect the stability of results about the correlation of CD44+/CD24- with OS in breast cancer. 